\title{
An empirical analysis of the welfare implications of the direct rebound effect
}

\author{
Ziyad Alfawzan • Anwar A. Gasim
}

Received: 5 June 2018 / Accepted: 5 March 2019/Published online: 27 March 2019

(C) The Author(s) 2019

\begin{abstract}
Improving the energy efficiency of an energy service, such as lighting, cooling, or driving, makes the service cheaper, normally leading consumers to demand more of it. This additional demand is known as the direct rebound effect. Rebound is often perceived negatively because it usually eliminates some of the expected energy savings. To determine if the direct rebound effect is welfare reducing, we undertake a cost-benefit analysis that compares the consumer surplus gained from direct rebound to the associated increase in negative externalities. Focusing on driving, the results reveal that the direct rebound effect is welfare reducing in most cases, as the consumer surplus gains were smaller than the increase in external costs. These external costs include greenhouse gas emissions, air pollution, congestion, and accidents. Finally, we show that overlooking the costs and benefits of the direct rebound effect can lead to a misleading cost-benefit evaluation of energy efficiency, particularly when rebound effects are large.
\end{abstract}

Keywords Rebound effect - Energy efficiency . Economic welfare $\cdot$ Cost-benefit analysis $\cdot$ Gasoline demand $\cdot$ Negative externalities

\footnotetext{
Z. Alfawzan · A. A. Gasim $(\bowtie)$

King Abdullah Petroleum Studies and Research Center

(KAPSARC), Riyadh, Saudi Arabia

e-mail: Anwar.Gasim@kapsarc.org
}

\author{
Abbreviations \\ VKT Vehicle kilometers traveled \\ GHG Greenhouse gas
}

\section{Introduction}

Energy is consumed to provide an energy service, such as lighting, cooling, or driving, while capital equipment is used to convert the energy into an energy service. A passenger car, for example, is used to convert gasoline into driving or vehicle kilometers traveled (VKT). Similarly, a light bulb is used to convert electricity into lighting.

When the energy efficiency of capital equipment improves, economic agents tend to adjust their behavior by consuming more of the energy service. This behavioral response, which reduces the expected energy savings from improved energy efficiency, is known as the rebound effect. Economic agents will normally alter their behavior when energy efficiency improves because the relative price of the energy service decreases. This change in relative prices leads to a change in demand. The price of the energy service is often called an "implicit price" because it is not directly seen by consumers. For example, a consumer may see the price of electricity on their bill, but it would not show the implicit price of lighting or air conditioning. The implicit price of an energy service depends on both the price of energy and the efficiency of the capital equipment (in addition to other factors). The implicit price of driving a 
car, for example, depends on the price of gasoline and the energy efficiency of the vehicle. Just as a fall in the price of gasoline would result in a fall in the implicit price of driving, a more energy efficient car will also make it cheaper to drive. This normally leads to increased VKT, giving rise to the rebound effect. ${ }^{1}$

Although the rebound effect is the economically expected outcome of improved energy efficiency, as noted by Jevons (1865) more than a century ago, many studies have discussed the need to mitigate rebound (for example, Herring and Roy 2007; Ouyang et al. 2010; Gloger 2011; Maxwell et al. 2011; van den Bergh 2011; Otto et al. 2014; Brown and Wang 2017). Rebound is often perceived as a negative phenomenon that works against the intended objectives of energy efficiency: namely to reduce energy consumption and greenhouse gas (GHG) emissions.

However, a few studies have noted that the rebound effect may be welfare enhancing (Hobbs 1991; Borenstein 2015; Chan and Gillingham 2015). Chan and Gillingham (2015) developed a theoretical microeconomic framework for studying the welfare implications of rebound. They showed that in the absence of externalities, the rebound effect is always welfare enhancing. With externalities, however, the welfare implications depend on which is bigger: the benefit from additional consumption of the energy service or the cost associated with that additional consumption.

Measuring the welfare implications of rebound is critical because it affects the welfare implications of energy efficiency policymaking. An energy efficiency improvement that has larger benefits than costs (in other words, welfare enhancing) may turn out to be welfare reducing after accounting for the rebound effect. Many economic evaluations of energy efficiency, however, have been done through a narrow lens that focuses only on the upfront capital costs and the monetary benefits from reduced energy consumption (Clinch and Healy 2001). Such an incomplete approach to evaluating energy efficiency overlooks the costs and benefits of rebound, which, as we will demonstrate, can lead to a misleading evaluation of energy efficiency.

This study is, to the best of our knowledge, the first to quantify the benefits and costs of the direct rebound effect for a large number of countries and consider the

\footnotetext{
${ }^{1}$ We use the term 'driving' interchangeably with VKT. We also use the kilometer as the unit of distance. Therefore, the term 'price of driving' denotes the price of a single VKT
}

welfare implications. Our empirical analysis initially focuses on driving as the energy service due to several factors. First, road transport accounts for a large share of final energy consumption in most economies around the world (IEA 2016a). Second, many governments have successfully implemented energy efficiency policies in this sector. According to the IEA (2016b), 74\% of the global road transport sector is covered by energy efficiency policies, mostly in the form of fuel economy standards. $^{2}$ Third, estimating the rebound effect from more energy efficient passenger cars is relatively straightforward since many countries rely on a single source of fuel (gasoline in most countries) to power their vehicles. This is described by Hunt and Ryan (2014) and Chan and Gillingham (2015) as 'single-energy singleservice.' Estimating the rebound effect becomes more complicated when there are multiple sources of energy and multiple services involved, such as the case of electricity, which provides lighting, heating, and air conditioning, in addition to many other services.

\section{Literature review}

More than a century ago, Jevons (1865) conjectured that an improvement in energy efficiency would not necessarily lead to reduced energy use. However, little attention was given to this effect until many years later following a paper published by Khazzoom (1980), which suggested that energy efficiency standards may not lead to significant energy savings because of the increased demand for the energy service. Dublin et al. (1986) stated that "energy-efficient appliances reduce the marginal price of the services they deliver," and that this results in "energy savings that are smaller than those engineering techniques generally project" (p. 310). Furthermore, Frey and Labay (1988) showed there was a consistent shortfall between forecasted and actual energy savings following an energy retrofit. They referred to this phenomenon as the take-back effect and suggested that the shortfall may be as large as 35\%. Henly et al. (1988) discussed the rebound effect and described it as "entirely consistent with economic behavior" (p. 164). Brookes (1990, 1992, 1993) discussed the fallacies

\footnotetext{
2 There is a difference between energy efficiency and fuel economy. A heavy vehicle, for example, may have an engine that is more thermodynamically efficient that a lighter vehicle. However, its heavier weight may relegate it to having worse fuel economy.
} 
associated with energy efficiency because of the rebound effect, focusing on claims that energy efficiency represented a fifth fuel.

Researchers now classify the rebound effect into different types: direct, indirect, and economy-wide rebound. The different types of rebound effects are best illustrated through an example. Consider a consumer that upgrades to a more efficient passenger car. The relatively lower price of driving due to the more efficient car will likely spur the owner to drive more, resulting in higher fuel consumption. This is the direct rebound effect. The relatively lower price of driving will also free up some of that consumer's income, which can be spent on other goods and services. Given that other goods and services generally require energy to be produced, an increase in their consumption will stimulate greater energy consumption in other areas of the economy. This is the indirect rebound effect. The direct and indirect rebound effects can alter the prices and consumption patterns of goods and services across the economy, together giving rise to an economy-wide rebound effect.

Greene (1992) was one of the first to measure the direct rebound effect from light-duty vehicle efficiency improvements in the USA. He estimated its size to be between 5 and $15 \%$ using price elasticities. Other seminal articles that measured the size of the direct rebound effect include Berkhout et al. (2000) for the Netherlands, Greening et al. (2000) for the USA, and Roy (2000) for India. All these studies relied on the use of energy price elasticities as proxies for measuring the size of the direct rebound effect.

It has become common to measure the direct rebound effect using energy price elasticities. Arguably, the most widely used definition states that the direct rebound effect is equal to the negative of the energy price elasticity (Sorrell and Dimitropoulos 2008). With this definition in hand, any estimated energy demand model that provides an estimate for the energy price elasticity would also implicitly provide an estimate for the direct rebound effect.

Other studies have used a general equilibrium approach instead to measure rebound (direct, indirect, and economy-wide). Dufournaud et al. (1994) were the first to model the rebound effect using an applied general equilibrium model, focusing on the rebound effect from energy efficient wood burning stoves in the Sudan. Subsequently, Grepperud and Rasmussen (2004) used a general equilibrium model to explore the size of the rebound effect in different sectors of Norway's national economy. General equilibrium methods have since been used in subsequent studies to measure economy-wide rebound effects, such as Liang et al. (2009) for China, Allan et al. (2009) for the UK, and Wei (2010) for the world economy. In addition to general equilibrium methods, bottom-up models have also been used by researchers to estimate economy-wide rebound effects, such as Barker et al. (2007) for the UK and Barker et al. (2009) for the world economy.

Questions on the size of the rebound effect have received significant attention from researchers in the energy economics literature. However, as noted by Azevedo (2014), the "welfare changes resulting from rebound have also largely been ignored" (p. 393). In a recent paper, Chan and Gillingham (2015) were the first to explore rebound's welfare implications. In their study, they presented a theoretical framework of how the direct rebound effect may influence energy efficiency's welfare implications. We build on their work by empirically estimating the costs and benefits of the direct rebound effect in 100 countries. This is done by calibrating demand curves for driving (that is, VKT) and combining them with external cost data on a country-by-country basis to conduct the welfare analysis.

\section{Methodology}

This study employs a partial equilibrium approach to measure the costs and benefits of the direct rebound effect for 100 countries. Our analysis does not consider the indirect or economy-wide rebound effects, which would likely require a calibrated computable general equilibrium model (or possibly a detailed bottom-up model) for each of the 100 countries, which is far beyond the scope of a single paper. Our partial equilibrium approach allows us to extend the analysis to 100 countries and is sufficient for modeling the direct rebound effect.

Our partial equilibrium analysis rests on calibrated demand curves for driving. The demand curves are used to estimate both the consumer surplus gained and the external costs exacerbated by the direct rebound effect. The benefits (the consumer surplus gains) are then compared to the costs (the exacerbated externalities) to determine whether the direct rebound effect is welfare enhancing. 
We assume a $10 \%$ improvement in energy efficiency in the analysis that follows. However, it is worth noting that the size of the improvement (whether 5,10 , or $30 \%$ ) does not alter the welfare outcomes significantly. For very large improvements in energy efficiency, however, the methods used in this paper become less useful as the constant elasticity functions may not adequately capture how consumers would respond.

\section{Estimating the direct rebound effect using elasticities}

Our treatment begins with a general framework that links energy demand to energy service demand. As shown by Sorrell and Dimitropoulos (2008),

$S=\eta E$

If we consider driving as the energy service, $S$ would be the demand for driving (measured in kilometers), $\eta$ the average efficiency of gasoline vehicles (measured in kilometers per liter), and $E$ the demand for gasoline (measured in liters).

Using the framework presented by Sorrell and Dimitropoulos (2008), the implicit price of driving $\left(P_{S}\right)$ can be expressed as a function of the price of gasoline $\left(P_{E}\right)$ and the level of energy efficiency $(\eta) .^{3}$

$P_{S}=P_{E} / \eta$

Given the empirical nature of this study, we follow the approach used by Davis (2017), where he assumed that gasoline demand takes the form of a constant elasticity function. Davis (2017) calibrated the gasoline demand function for each country using price and demand data, and assumed a constant gasoline price elasticity of -0.6 . He then used the calibrated demand curves to estimate the deadweight loss and externalities associated with subsidies. In this paper, we employ the same functional form but use it to estimate the changes in surplus and externalities associated with the direct rebound effect. We also measure the welfare outcomes across a range of price elasticities instead of a single fixed elasticity.

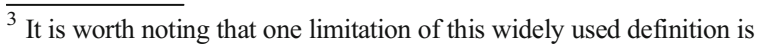
that it overlooks the time cost of driving, an important consideration for motorists (Small and Van Dender 2007). In the analysis that follows, we effectively assume that the time costs of driving are constant on the margin.
}

Following the approach in Davis (2017), we define the following demand curve for gasoline:

$E=A P_{E}{ }^{\alpha}$

where $A$ is a scale parameter and $\alpha$ the elasticity of gasoline demand with respect to its price.

We also define a constant elasticity demand curve for driving:

$S=K P_{S}{ }^{\beta}$

where $K$ is another scale parameter and $\beta$ the elasticity of driving with respect to its implicit price. This functional form allows an improvement in the energy efficiency of passenger cars to manifest as a pure price effect (Greening et al. 2000).

According to Sorrell (2009), the direct rebound effect is often defined to be the elasticity of the energy service with respect to energy efficiency. Denoting the elasticity of $a$ with respect to $b$ by $\varepsilon_{a, b}$, the direct rebound effect is therefore given by $\varepsilon_{S, \eta}$. Using the constant elasticity function, we can show that:

$$
\begin{aligned}
\varepsilon_{S, \eta} & =\frac{\partial S}{\partial \eta} \frac{\eta}{S}=\frac{\eta}{S} * \frac{\partial}{\partial \eta}\left(K \frac{P_{E}^{\beta}}{\eta^{\beta}}\right) \\
& =\frac{\eta K P_{E}^{\beta}}{S} *\left(-\frac{\beta}{\eta^{\beta+1}}\right)=-\beta \frac{K P_{E}^{\beta}}{S \eta^{\beta}}=-\beta
\end{aligned}
$$

With our constant elasticity function, the direct rebound effect is equal to the negative of the elasticity of driving with respect to its implicit price $\left(\varepsilon_{S, \eta}=-\varepsilon_{S, P_{S}}=-\beta\right)$.

These elasticity relationships have already been demonstrated more generally by Sorrell and Dimitropoulos (2008), Hunt and Ryan (2014), and Chan and Gillingham (2015). Furthermore, they demonstrated that in a single-energy single-service case, the elasticity of driving with respect to energy efficiency would be equal to the negative of the energy price elasticity:

$\varepsilon_{S, \eta}=-\varepsilon_{S, P_{S}}=-\beta=-\varepsilon_{E, P_{E}}=-\alpha$

In the single-energy single-service case, if the price elasticity of gasoline demand were estimated to be $\alpha=$ -0.2 , then the direct rebound effect would be $\varepsilon_{S, \eta}=0.2$. This implies that $20 \%$ of the expected energy savings would be lost due to the direct rebound effect. In fact, the direct rebound effect is usually expressed in terms of percentages. Thus, $\varepsilon_{S, \eta}=0.2$ would be interpreted as a direct rebound effect of $20 \%$. 
The energy price elasticity is not always a perfect proxy for measuring the direct rebound effect. It becomes a biased estimator when multiple energy sources and services are involved. Hunt and Ryan (2014) and Chan and Gillingham (2015) have proven that the direct rebound effect is equal to the negative of the energy price elasticity only in the single-energy single-service case. In the multipleenergy multiple-services case, different elasticity relationships emerge as demonstrated by Chan and Gillingham (2015):

$\varepsilon_{S, \eta}=-\varepsilon_{S, P_{S}} \neq-\varepsilon_{E, P_{E}}$

This relationship shows that the elasticity of the demand for driving with respect to its implicit price $\left(\varepsilon_{S, P_{S}}\right)$ reflects the size of the direct rebound effect even in the case of multiple-energy multiple-services. For this reason, the welfare results are presented for a range of elasticities, from $\varepsilon_{S, P_{S}}=-0.1$ to $\varepsilon_{S, P_{S}}=-0.9$, to account for cases where the gasoline price elasticity does not provide us with an indication of the size of the direct rebound effect.

In countries such as Saudi Arabia where almost all passenger cars are gasoline-based (IEA 2016a), the price elasticity of gasoline demand will provide a reliable estimate of the direct rebound effect. This is the same in India, where the primary fuel used by two-wheelers is gasoline. For such countries, the use of the energy price elasticity is suitable for estimating the direct rebound effect, as noted by Menon (2017) in the case of India. However, in countries such as France where consumers purchase both gasoline and diesel vehicles, the estimates will be less accurate. However, according to ExxonMobil (2016), gasoline is the primary fuel used in light-duty vehicles in most countries, and therefore the use of energy price elasticities for measuring the direct rebound effect is suitable in most cases.

\section{Estimating the benefits of energy efficiency and rebound}

When the energy efficiency of passenger cars improves, the implicit price of driving falls. The demand function for driving can then be used to predict the consumer surplus gained from this price decrease:

$$
\begin{aligned}
B_{C S} & =\int_{P_{S, A}}^{P_{S, B}} K P_{S}{ }^{\beta} d P_{S}=\frac{K}{\beta+1} *\left[P_{S, B}{ }^{\beta+1}-P_{S, A}{ }^{\beta+1}\right] \\
& =B_{M S}+B_{R}
\end{aligned}
$$

The prices $P_{S, B}$ and $P_{S, A}$ reflect the implicit prices of driving before and after the improvement, respectively, while $B_{C S}$ denotes the total consumer surplus gained from improved energy efficiency. The total gain can be broken down into two smaller areas, as illustrated in Fig. 1. The first area $B_{M S}$ reflects the monetary savings from improved energy efficiency, holding the demand for driving fixed. It can be calculated as follows:

$B_{M S}=\left(P_{S, B}-P_{S, A}\right) * S_{0}$

where $S_{0}$ denotes the initial demand for driving before the energy efficiency improvement. On the other hand, $S_{R}$ denotes the demand for driving after the direct rebound effect occurs.

The second area $B_{R}$ reflects the consumer surplus gained from additional driving. This can be calculated as follows:

$B_{R}=B_{C S}-B_{M S}$

There is also a third benefit from improved energy efficiency. Since gasoline consumption is associated with external costs such as air pollution and GHG emissions (Parry et al. 2014), any reduction in gasoline consumption will lead to a reduction in these externalities. The benefit from reducing these external costs can be calculated by multiplying the fall in gasoline consumption (measured in liters) by the externalities of air pollution and GHG emissions (measured in US\$ per liter), which are denoted by $\delta_{E}$ and obtained from the IMF (2016).

$B_{E C}=\left(E_{0}-E_{N R}\right) * \delta_{E}$

$B_{E C}$ denotes the total benefit from lower external costs, $E_{0}$ the gasoline consumption before the energy efficiency improvement, and $E_{N R}$ the gasoline consumption after the improvement, assuming no rebound, which is estimated as follows:

$E_{N R}=\frac{S_{0}}{\eta^{*}(1+10 \%)}$ 


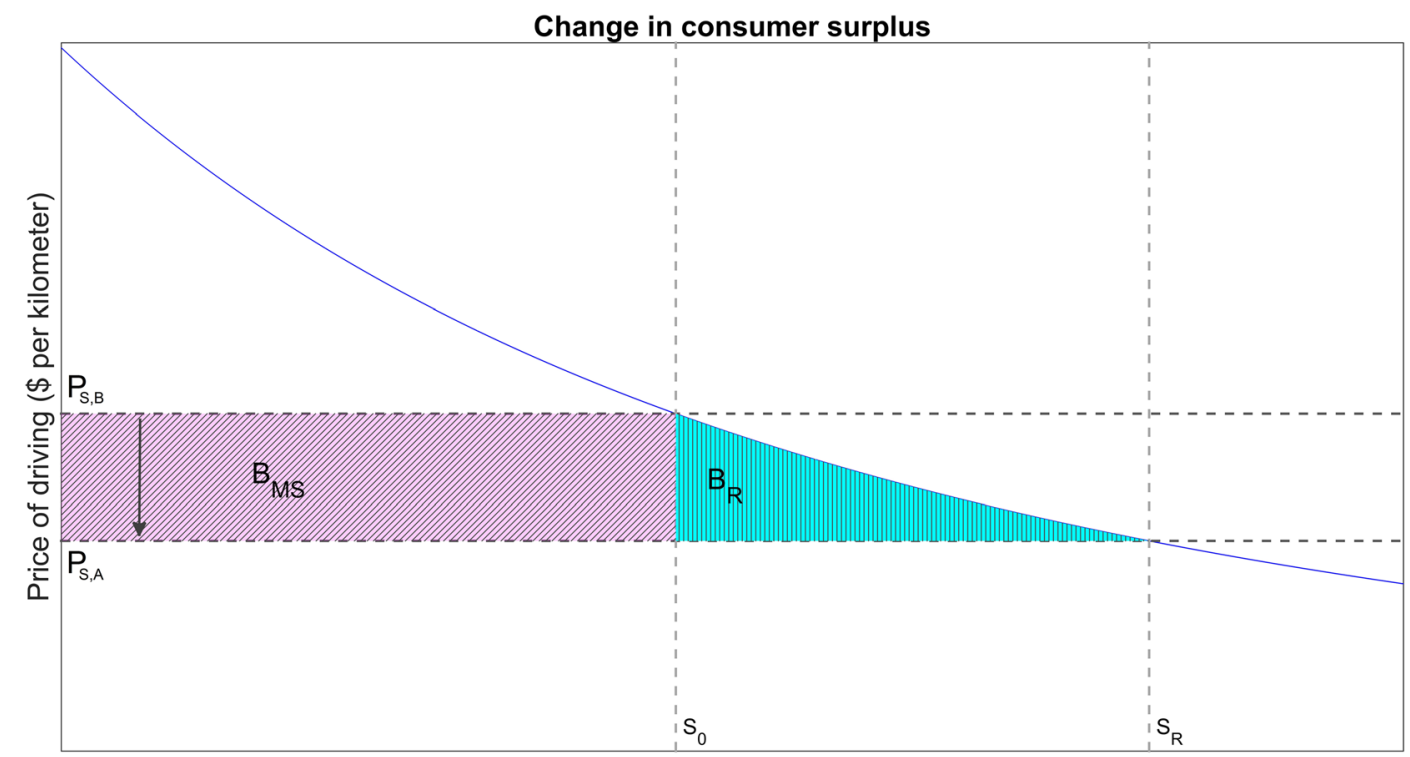

Vehicle kilometers travelled

Fig. 1 The consumer surplus gained following a fall in the implicit price of driving due to improved energy efficiency

To summarize, the total benefit from improved energy efficiency includes the benefit from monetary savings, the benefit due to the consumer surplus gained from additional driving, and the benefit from reduced external costs, as shown by the following equation:

$B_{E E}=B_{M S}+B_{R}+B_{E C}$

\section{Estimating the costs of energy efficiency and rebound}

Although energy efficiency delivers multiple benefits, there are also multiple costs that need to be accounted for. There is first the capital cost of an energy efficiency improvement. This can include the cost of the initial purchase, depreciation, and vehicle registration. In this paper, we assume that the capital cost is zero. We therefore conduct a welfare analysis of a costless, exogenous energy efficiency improvement-a common assumption in rebound studies. The goal of this assumption is to turn the focus towards an often overlooked cost: the cost of the direct rebound effect.

The cost of the direct rebound effect can be broken down into two segments. The first segment is due to the energy-related external costs that arise from the additional consumption of gasoline above a scenario in which there was no rebound. This cost can be calculated by multiplying the additional consumption by the externalities of air pollution and GHG emissions.

$C_{E}=\left(E_{R}-E_{N R}\right) * \delta_{E}$

$C_{E}$ denotes the total energy-related cost of the direct rebound effect, while $E_{R}$ denotes the demand for gasoline following rebound, which can be estimated through the following equations:

$E_{R}=\frac{S_{R}}{\eta^{*}(1+10 \%)}$

$S_{R}=K P_{S, A}^{\beta}$

The second segment is due to the external costs that arise from the increase in VKT. The direct rebound effect implies that consumers are driving more, leading to greater congestion and accidents. We can estimate this cost by multiplying the additional driving by the externalities of congestion and accidents (measured in US\$ per kilometer), which are denoted by $\delta_{S}$. As mentioned previously, $\delta_{E}$ and $\delta_{S}$ are obtained from the IMF (2016).

$C_{S}=\left(S_{R}-S_{0}\right) * \delta_{S}$ 
where $C_{S}$ denotes the total service-related cost of the direct rebound effect.

Thus, the total cost of the direct rebound $\operatorname{effect}\left(C_{R}\right)$ is equal to the energy-related external costs plus the service-related external costs.

$C_{R}=C_{E}+C_{S}$

Given that the upfront capital costs are assumed zero $\left(C_{c}=0\right)$, the total cost of an energy efficiency improvement $\left(C_{E E}\right)$ is therefore equal to the total cost of the direct rebound effect.

$C_{E E}=C_{C}+C_{R}=C_{R}$

\section{Estimating the welfare implications of energy efficiency and rebound}

The welfare implications of energy efficiency and rebound are governed by the relative sizes of the benefits and costs. For the direct rebound effect, the welfare implications are determined as follows:

$B C R_{R}=\frac{B_{R}}{C_{R}}$

The direct rebound effect is therefore welfare enhancing when its benefit-to-cost ratio $\left(B C R_{R}\right)$ is greater than one, that is, when the consumer surplus from additional driving outweighs the associated external costs.

Similarly, the welfare implications of an energy efficiency improvement with zero upfront capital costs are determined as follows:

$B C R_{E E}=\frac{B_{E E}}{C_{E E}}=\frac{B_{E E}}{C_{R}}$

An efficiency improvement is therefore welfare enhancing when its benefit-to-cost ratio $\left(B C R_{E E}\right)$ is greater than one.

\section{Welfare implications when prices deviate from private cost}

If gasoline were sold at private cost, there would be no need to account for the impact on the government. However, gasoline is taxed by some governments and subsidized by others. Deviations in the price of gasoline from private cost can therefore affect government spending/revenues and consequently the welfare results.

As noted by Borenstein (2015), the savings that a consumer gains from improved energy efficiency may be different from the economy-wide savings because of non-marginal-cost pricing. ${ }^{4}$ For example, if the private cost of a liter of gasoline were $\$ 2$, but the consumer only pays $\$ 1$, then the consumer will only gain $\$ 1$ for each liter of gasoline saved. However, the economy-wide monetary savings would be $\$ 2$ since the government, which was subsidizing the gasoline, would also gain $\$$.

We account for the impact of improved energy efficiency on the government, assuming no rebound initially, as follows:

$G_{N R}=\left(P_{E}{ }^{*}-P_{E}\right) *\left(E_{0}-E_{N R}\right)$

where $G_{N R}$ denotes the gain or loss to the government from energy efficiency under a zero rebound scenario, $P_{E}{ }^{*}$ the international price of a liter of gasoline, which is obtained from Platts (2016), and $P_{E}$ the domestic "price at the pump", obtained from the World Bank (2016).

We account for the impact of the direct rebound effect on the government $\left(G_{R}\right)$, through the following equation:

$G_{R}=\left(P_{E}{ }^{*}-P_{E}\right) *\left(E_{N R}-E_{R}\right)$

To include the government in the welfare analysis of rebound, the absolute value of the variable $G_{R}$ is added to either the benefits (when $G_{R}$ is positive) or costs (when $\mathrm{G}_{R}$ is negative) in Eq. (20).

We account for the net impact of the energy efficiency improvement (including rebound) on the government as follows:

$G_{E E}=G_{N R}+G_{R}=\left(P_{E}{ }^{*}-P_{E}\right) *\left(E_{0}-E_{R}\right)$

To include the government in the welfare analysis of energy efficiency, the absolute value of the variable $G_{E E}$ is added to either the benefits or costs in Eq. (21), depending on its sign.

Appendix 1 provides an example of how these methods are combined, using data specific to Saudi Arabia.

${ }^{4}$ We prefer the term non-private-cost pricing given that in countries such as Saudi Arabia gasoline may be sold at low administered prices that lie at or above marginal cost but below international market prices. 


\section{Data}

All data are collected for the year 2010. The choice of study year was largely determined by the external cost data, which were estimated by the IMF (2016) for 2010. These external costs have likely changed in recent years for most countries, but to the best of our knowledge, there are no estimates for external costs on a country-bycountry basis more recent than 2010 . The external cost data are arguably the most important input to our welfare analysis, and are directly taken from the IMF's (2016) database on 'Getting Energy Prices Right'. The IMF (2016) data originate from a study by Parry et al. (2014) that estimated the external costs of air pollution, GHG emissions, congestion, and accidents associated with driving on a country-by-country basis for the year 2010. We refer to air pollution and GHG emissions as energy-related external costs, while we refer to congestion and accidents as service-related external costs.

Determining whether a cost is internal or external can be tricky. For both congestion and accidents, there are internal and external components to each. An internal cost is one that consumers account for when making decisions regarding driving, while they do not account for the external costs that are ultimately borne by others. In the case of accidents, Parry et al. (2014) viewed the damage that drivers pose to pedestrians and cyclists as an external cost. On the other hand, they viewed the cost of injury to occupants in single-vehicle collisions as internal, because drivers consider such risks when deciding how much to drive. For multi-vehicle collisions, Parry et al. (2014) appeared to treat $25 \%$ of the damages as external. In the case of congestion, Parry et al. (2014) estimated the external cost by first calculating the total congestion cost to all passengers. Dividing the total cost by the traffic volume produces the average congestion cost per kilometer, which Parry et al. (2014) assumed is internal. On the other hand, differentiating the total cost with respect to the traffic volume produces the marginal congestion cost per kilometer. This marginal cost is made up of the average cost plus an additional term, which captures the cost to passengers of other vehicles, which is not taken into account by the driver (they only account for the cost to themselves, which is captured by the average cost). The additional term is therefore assumed by Parry et al. (2014) to be the external cost of congestion. More detailed information on the methods and assumptions behind the external cost data used in this paper can be found in Parry et al. (2014).
Gasoline demand data were collected from the IEA's (2016a) World Energy Statistics. Gasoline prices at the pump were from the World Bank (2016). Fuel economies, which were needed to convert the demand for gasoline into demand for driving, were also obtained from the IMF (2016). It should be noted, however, that the fuel economies in the IMF (2016) database were estimated on a region-by-region basis due to data limitations.

Finally, four different spot prices were used to measure the gasoline subsidy/tax in each country: For Middle Eastern countries, the average 2010 'free on board' spot price of 95-octane gasoline at Jebel Ali port (Platts 2016); for Asian countries, the 2010 gasoline spot price at Singapore port (Platts 2016); for European and African countries, the 2010 Eurobob gasoline spot price at Rotterdam port (Platts 2016); for North and South American countries, an average of the 2010 New York Harbor and U.S. Gulf Coast Conventional Gasoline spot prices (Reuters 2016).

\section{Results and discussion}

Energy efficiency is often thought to be welfare enhancing so long as the monetary savings from improved energy efficiency are greater than the capital costs. However, as we have discussed, such thinking overlooks other important benefits and costs, mainly the impact of the rebound effect. In this paper, we quantify the benefits and costs of the direct rebound effect and demonstrate its welfare implications. We begin with the welfare results from the simplest case: a free energy efficiency improvement and zero rebound.

The welfare implications of a free energy efficiency improvement

Given that the upfront capital cost of a free energy efficiency improvement is, by definition, zero, and that we assume zero rebound, the total cost of the improvement is therefore zero. As a result, such an improvement will always have larger benefits than costs and be welfare enhancing. The benefits stem from both the cash savings that consumers are rewarded with because of reduced gasoline demand and the associated reduction in gasoline-related external costs. The demand curve for driving in this simple case is perfectly price inelastic, so that the fall in the implicit price of driving due to 
improved efficiency does not stimulate any additional demand for driving. As a result, VKT remains fixed and there are no changes in the service-related external costs.

\section{The welfare implications of the direct rebound effect}

The direct rebound effect was found to be welfare reducing in most countries, as shown in Table 1 , in which the welfare results are presented across a range of elasticities. The elasticities in question are the elasticities of the demand for driving with respect to its implicit price $\left(\varepsilon_{S, P_{S}}\right)$, which reflect the size of the direct rebound effect. For example, an elasticity of $\varepsilon_{S, P_{S}}=-0.3$ reflects a direct rebound effect of $30 \%$. For countries where driving can be described as single-energy single-service, this elasticity is also equal to the gasoline price elasticity $\left(\varepsilon_{E, P_{E}}\right)$. The results marked by $*$ in Tables 1 and 2 reflect the welfare results for $\varepsilon_{S, P_{S}}=\varepsilon_{E, P_{E}}$, where the gasoline price elasticities were obtained from Dahl (2012). However, for some countries, the gasoline price elasticity may not accurately capture the direct rebound effect because of the existence of multiple fuels for driving, and therefore $\varepsilon_{S, P_{S}} \neq \varepsilon_{E, P_{E}}$. The welfare results are thus presented for a range of elasticities, from $\varepsilon_{S, P_{S}}=-0.1$ to $\varepsilon_{S, P_{S}}=-0.9$, or in other words, for direct rebounds effects of 10 to $90 \%$.

The welfare results in Table 1 suggest that regardless of the size of the direct rebound effect, the welfare implications remain largely unchanged (minor decreases in the benefit-to-cost ratio at larger elasticities are not visible in Table 1). Most countries were found to have welfare reducing direct rebound effects following a $10 \%$ improvement in energy efficiency. Furthermore, the direct rebound effect was found to be considerably more welfare reducing in countries that had some combination of low gasoline prices and medium to high external costs. Low gasoline prices imply that the consumer surplus gained from the same percentage improvement in energy efficiency is lower than it could have been at higher prices (see Fig. 2). Thus, when energy efficiency improves in a country with low fuel prices, the additional fall in the price of driving because of improved efficiency provides little benefit to consumers since driving is already very cheap. High external costs also play an important role. Unlike the external cost of GHG emissions, which is the same for all countries, the external costs of congestion and accidents vary markedly. On the one hand, the cost of congestion estimated by Parry et al. (2014) depended on both how much time is wasted in traffic and the monetary value of that time, which in turn is a function of income. The higher the income level in a country, the higher the cost of congestion. On the other hand, the cost of accidents they estimated depended on both income and road safety levels. In summary, countries with low gasoline prices, medium to high congestion costs, and/or medium to high accident costs were found to have the worst (that is, with the smallest benefit-to-cost ratio) direct rebound effects.

Is the direct rebound effect welfare reducing more often than not, even for improvements in the energy efficiency of other energy services? An improvement in the efficiency of lighting or cooling for example would give rise to a rebound effect that generates external costs in air pollution and GHG emissions only (although there may be other minor external costs). We can roughly approximate the potential welfare implications of such an improvement by setting the external costs of congestion and accidents to zero and then reestimating the benefit-to-cost ratio of the direct rebound effect from the previous analysis (see Appendix 2 for more details). The results reveal welfare enhancing direct rebound effects in most cases when the external costs of congestion and accidents are set to zero, suggesting that direct rebound may be welfare enhancing for other energy services.

There may be benefits associated with the direct rebound effect that have not been captured in our analysis. These benefits may be thought of as external or social benefits, in analogy to the external costs that are considered in this paper. External benefits would reflect welfare gains that are not captured by consumer surplus (Schwartz 2005). For example, the lower cost of driving due to improved efficiency may allow a person to drive greater distances each day, potentially providing access to better job opportunities in farther areas. These opportunities may then contribute to greater productivity in the economy. Such external benefits are difficult to estimate, but it is clear that they would improve rebound's welfare outcomes. Further studies on these external benefits, however, are needed before they could be incorporated into studies such as this one. Nevertheless, capturing these benefits will improve the welfare outcomes for the direct rebound effect. Therefore, the benefit-to-cost ratios presented in Table 1 may be thought of as lower bound estimates. 
Table 1 The benefit-to-cost ratio of the direct rebound effect following a 10\% improvement in the energy efficiency of passenger cars. The * denotes the welfare results obtained using Dahl's (2012) elasticities

\begin{tabular}{|c|c|c|c|c|c|c|c|c|c|c|c|}
\hline \multirow[t]{2}{*}{ Country } & \multirow[t]{2}{*}{ Total external cost } & \multirow[t]{2}{*}{ Gasoline price } & \multicolumn{9}{|c|}{ Benefit-to-cost ratio of rebound $\left(B_{R}\right)$ for a range of elasticities $\left(\varepsilon_{S, P_{S}}\right)$} \\
\hline & & & -0.1 & -0.2 & -0.3 & -0.4 & -0.5 & -0.6 & -0.7 & -0.8 & -0.9 \\
\hline Bahrain & Low & Low & 0.0 & 0.0 & 0.0 & 0.0 & $0.0 *$ & 0.0 & 0.0 & 0.0 & 0.0 \\
\hline Brunei & Low & Low & 0.0 & $0.0 *$ & 0.0 & 0.0 & 0.0 & 0.0 & 0.0 & 0.0 & 0.0 \\
\hline Egypt & Low & Low & 0.0 & $0.0 *$ & 0.0 & 0.0 & 0.0 & 0.0 & 0.0 & 0.0 & 0.0 \\
\hline Nigeria & Low & Low & 0.0 & $0.0 *$ & 0.0 & 0.0 & 0.0 & 0.0 & 0.0 & 0.0 & 0.0 \\
\hline Bolivia & Low & Medium & 0.3 & $0.3 *$ & 0.3 & 0.3 & 0.3 & 0.3 & 0.3 & 0.3 & 0.3 \\
\hline Ecuador & Low & Medium & 0.0 & $0.0 *$ & 0.0 & 0.0 & 0.0 & 0.0 & 0.0 & 0.0 & 0.0 \\
\hline Ethiopia & Low & Medium & 0.5 & 0.5 & $0.5^{*}$ & 0.5 & 0.5 & 0.5 & 0.5 & 0.5 & 0.5 \\
\hline Ghana & Low & Medium & 0.6 & 0.6 & $0.6^{*}$ & 0.6 & 0.6 & 0.6 & 0.6 & 0.6 & 0.6 \\
\hline Indonesia & Low & Medium & 0.4 & $0.4 *$ & 0.4 & 0.4 & 0.4 & 0.4 & 0.4 & 0.4 & 0.4 \\
\hline Mexico & Low & Medium & 0.4 & 0.4 & $0.4^{*}$ & 0.4 & 0.4 & 0.4 & 0.4 & 0.4 & 0.4 \\
\hline Pakistan & Low & Medium & 0.6 & 0.6 & 0.6 & $0.6^{*}$ & 0.6 & 0.6 & 0.6 & 0.6 & 0.6 \\
\hline Sudan & Low & Medium & 0.7 & 0.7 & $0.7 *$ & 0.7 & 0.7 & 0.7 & 0.7 & 0.7 & 0.7 \\
\hline Vietnam & Low & Medium & 0.4 & 0.4 & $0.4^{*}$ & 0.4 & 0.4 & 0.4 & 0.4 & 0.4 & 0.4 \\
\hline Bangladesh & Low & High & $0.7^{*}$ & 0.7 & 0.7 & 0.7 & 0.7 & 0.7 & 0.7 & 0.7 & 0.7 \\
\hline Belarus & Low & High & 0.7 & 0.7 & $0.7 *$ & 0.7 & 0.7 & 0.7 & 0.7 & 0.7 & 0.7 \\
\hline Benin & Low & High & 1.9 & 1.9 & $1.9^{*}$ & 1.9 & 1.9 & 1.9 & 1.9 & 1.9 & 1.9 \\
\hline Bosnia & Low & High & 1.2 & 1.2 & $1.2 *$ & 1.2 & 1.2 & 1.2 & 1.2 & 1.2 & 1.2 \\
\hline Brazil & Low & High & 1.2 & 1.2 & $1.2 *$ & 1.2 & 1.2 & 1.2 & 1.2 & 1.2 & 1.2 \\
\hline Cameroon & Low & High & 2.9 & 2.9 & $2.9^{*}$ & 2.9 & 2.9 & 2.9 & 2.9 & 2.9 & 2.9 \\
\hline Estonia & Low & High & 2.6 & 2.6 & $2.6^{*}$ & 2.6 & 2.6 & 2.6 & 2.6 & 2.6 & 2.6 \\
\hline Georgia & Low & High & 0.9 & 0.9 & $0.9^{*}$ & 0.9 & 0.9 & 0.9 & 0.9 & 0.9 & 0.9 \\
\hline Honduras & Low & High & 0.6 & 0.6 & $0.6^{*}$ & 0.6 & 0.6 & 0.6 & 0.6 & 0.6 & 0.6 \\
\hline Ivory Coast & Low & High & $1.5^{*}$ & 1.5 & 1.5 & 1.5 & 1.5 & 1.5 & 1.5 & 1.5 & 1.5 \\
\hline Jordan & Low & High & 0.7 & 0.7 & $0.7 *$ & 0.7 & 0.7 & 0.7 & 0.7 & 0.7 & 0.7 \\
\hline Mozambique & Low & High & 0.7 & 0.7 & $0.7^{*}$ & 0.7 & 0.7 & 0.7 & 0.7 & 0.7 & 0.7 \\
\hline Nicaragua & Low & High & 0.7 & 0.7 & $0.7 *$ & 0.7 & 0.7 & 0.7 & 0.7 & 0.7 & 0.7 \\
\hline Philippines & Low & High & 1.0 & 1.0 & 1.0 & $1.0^{*}$ & 1.0 & 1.0 & 1.0 & 1.0 & 1.0 \\
\hline Senegal & Low & High & 3.3 & 3.3 & $3.3 *$ & 3.3 & 3.3 & 3.3 & 3.3 & 3.3 & 3.3 \\
\hline Slovenia & Low & High & 1.4 & 1.4 & $1.4 *$ & 1.4 & 1.4 & 1.4 & 1.4 & 1.4 & 1.4 \\
\hline Thailand & Low & High & 1.0 & $1.0^{*}$ & 1.0 & 1.0 & 1.0 & 1.0 & 1.0 & 1.0 & 1.0 \\
\hline Togo & Low & High & 2.1 & 2.1 & $2.1 *$ & 2.1 & 2.1 & 2.1 & 2.1 & 2.1 & 2.1 \\
\hline Ukraine & Low & High & $0.7 *$ & 0.7 & 0.7 & 0.7 & 0.7 & 0.7 & 0.7 & 0.7 & 0.7 \\
\hline Zimbabwe & Low & High & 2.2 & $2.2 *$ & 2.2 & 2.2 & 2.2 & 2.2 & 2.2 & 2.2 & 2.2 \\
\hline Iran & Medium & Low & 0.0 & $0.0 *$ & 0.0 & 0.0 & 0.0 & 0.0 & 0.0 & 0.0 & 0.0 \\
\hline Oman & Medium & Low & 0.0 & 0.0 & 0.0 & 0.0 & $0.0^{*}$ & 0.0 & 0.0 & 0.0 & 0.0 \\
\hline Saudi Arabia & Medium & Low & $0.0 *$ & 0.0 & 0.0 & 0.0 & 0.0 & 0.0 & 0.0 & 0.0 & 0.0 \\
\hline Venezuela & Medium & Low & $0.0^{*}$ & 0.0 & 0.0 & 0.0 & 0.0 & 0.0 & 0.0 & 0.0 & 0.0 \\
\hline Azerbaijan & Medium & Medium & 0.2 & $0.2 *$ & 0.2 & 0.2 & 0.2 & 0.2 & 0.2 & 0.2 & 0.2 \\
\hline Botswana & Medium & Medium & 0.4 & 0.4 & $0.4 *$ & 0.4 & 0.4 & 0.4 & 0.4 & 0.4 & 0.4 \\
\hline El Salvador & Medium & Medium & 0.4 & 0.4 & $0.4 *$ & 0.4 & 0.4 & 0.4 & 0.4 & 0.4 & 0.4 \\
\hline Kazakhstan & Medium & Medium & 0.2 & 0.2 & $0.2 *$ & 0.2 & 0.2 & 0.2 & 0.2 & 0.2 & 0.2 \\
\hline
\end{tabular}


Table 1 (continued)

\begin{tabular}{|c|c|c|c|c|c|c|c|c|c|c|c|}
\hline \multirow[t]{2}{*}{ Country } & \multirow[t]{2}{*}{ Total external cost } & \multirow[t]{2}{*}{ Gasoline price } & \multicolumn{9}{|c|}{ Benefit-to-cost ratio of rebound $\left(B_{R}\right)$ for a range of elasticities $\left(\varepsilon_{S, P_{S}}\right)$} \\
\hline & & & -0.1 & -0.2 & -0.3 & -0.4 & -0.5 & -0.6 & -0.7 & -0.8 & -0.9 \\
\hline Malaysia & Medium & Medium & $0.1^{*}$ & 0.1 & 0.1 & 0.1 & 0.1 & 0.1 & 0.1 & 0.1 & 0.1 \\
\hline Tunisia & Medium & Medium & 0.4 & $0.4 *$ & 0.4 & 0.4 & 0.4 & 0.4 & 0.4 & 0.4 & 0.4 \\
\hline United States & Medium & Medium & 0.2 & 0.2 & $0.2^{*}$ & 0.2 & 0.2 & 0.2 & 0.2 & 0.2 & 0.2 \\
\hline Albania & Medium & High & 0.9 & 0.9 & $0.9^{*}$ & 0.9 & 0.9 & 0.9 & 0.9 & 0.9 & 0.9 \\
\hline Bulgaria & Medium & High & 0.9 & 0.9 & $0.9^{*}$ & 0.9 & 0.9 & 0.9 & 0.9 & 0.9 & 0.9 \\
\hline Chile & Medium & High & 0.7 & 0.7 & $0.7 *$ & 0.7 & 0.7 & 0.7 & 0.7 & 0.7 & 0.7 \\
\hline China, P.R. & Medium & High & 0.5 & 0.5 & $0.5^{*}$ & 0.5 & 0.5 & 0.5 & 0.5 & 0.5 & 0.5 \\
\hline Costa Rica & Medium & High & 0.6 & 0.6 & 0.6 & $0.6^{*}$ & 0.6 & 0.6 & 0.6 & 0.6 & 0.6 \\
\hline Croatia & Medium & High & 1.1 & 1.1 & $1.1^{*}$ & 1.1 & 1.1 & 1.1 & 1.1 & 1.1 & 1.1 \\
\hline Cyprus & Medium & High & 0.9 & 0.9 & $0.9^{*}$ & 0.9 & 0.9 & 0.9 & 0.9 & 0.9 & 0.9 \\
\hline Czech R. & Medium & High & 1.0 & 1.0 & $1.0^{*}$ & 1.0 & 1.0 & 1.0 & 1.0 & 1.0 & 1.0 \\
\hline Hungary & Medium & High & 1.1 & 1.1 & $1.1^{*}$ & 1.1 & 1.1 & 1.1 & 1.1 & 1.1 & 1.1 \\
\hline Kenya & Medium & High & 0.9 & 0.9 & $0.9^{*}$ & 0.9 & 0.9 & 0.9 & 0.9 & 0.9 & 0.9 \\
\hline Latvia & Medium & High & 1.1 & 1.1 & $1.1^{*}$ & 1.1 & 1.1 & 1.1 & 1.1 & 1.1 & 1.1 \\
\hline Lithuania & Medium & High & 0.9 & 0.9 & $0.9^{*}$ & 0.9 & 0.9 & 0.9 & 0.9 & 0.9 & 0.9 \\
\hline Malta & Medium & High & 0.9 & 0.9 & $0.9^{*}$ & 0.9 & 0.9 & 0.9 & 0.9 & 0.9 & 0.9 \\
\hline Mongolia & Medium & High & 0.6 & 0.6 & $0.6^{*}$ & 0.6 & 0.6 & 0.6 & 0.6 & 0.6 & 0.6 \\
\hline New Zealand & Medium & High & $0.9^{*}$ & 0.9 & 0.9 & 0.9 & 0.9 & 0.9 & 0.9 & 0.9 & 0.9 \\
\hline Paraguay & Medium & High & 0.7 & $0.7 *$ & 0.7 & 0.7 & 0.7 & 0.7 & 0.7 & 0.7 & 0.7 \\
\hline Poland & Medium & High & 0.9 & 0.9 & $0.9^{*}$ & 0.9 & 0.9 & 0.9 & 0.9 & 0.9 & 0.9 \\
\hline Romania & Medium & High & 0.8 & 0.8 & $0.8^{*}$ & 0.8 & 0.8 & 0.8 & 0.8 & 0.8 & 0.8 \\
\hline Slovakia & Medium & High & 1.1 & 1.1 & $1.1^{*}$ & 1.1 & 1.1 & 1.1 & 1.1 & 1.1 & 1.1 \\
\hline Sri Lanka & Medium & High & 0.5 & 0.5 & 0.5 & $0.5^{*}$ & 0.5 & 0.5 & 0.5 & 0.5 & 0.5 \\
\hline Israel & Medium & Very high & 1.1 & $1.1 *$ & 1.1 & 1.1 & 1.1 & 1.1 & 1.1 & 1.1 & 1.1 \\
\hline Portugal & Medium & Very high & 1.1 & 1.1 & $1.1^{*}$ & 1.1 & 1.1 & 1.1 & 1.1 & 1.1 & 1.1 \\
\hline Kuwait & High & Low & $0.0^{*}$ & 0.0 & 0.0 & 0.0 & 0.0 & 0.0 & 0.0 & 0.0 & 0.0 \\
\hline Russia & High & Medium & $0.2^{*}$ & 0.2 & 0.2 & 0.2 & 0.2 & 0.2 & 0.2 & 0.2 & 0.2 \\
\hline Syria & High & Medium & 0.2 & $0.2 *$ & 0.2 & 0.2 & 0.2 & 0.2 & 0.2 & 0.2 & 0.2 \\
\hline Australia & High & High & 0.5 & 0.5 & $0.5^{*}$ & 0.5 & 0.5 & 0.5 & 0.5 & 0.5 & 0.5 \\
\hline Austria & High & High & 0.8 & 0.8 & 0.8 & 0.8 & $0.8^{*}$ & 0.8 & 0.8 & 0.8 & 0.8 \\
\hline Cambodia & High & High & 0.4 & 0.4 & $0.4^{*}$ & 0.4 & 0.4 & 0.4 & 0.4 & 0.4 & 0.4 \\
\hline Canada & High & High & 0.5 & 0.5 & 0.5 & 0.5 & $0.5^{*}$ & 0.5 & 0.5 & 0.5 & 0.5 \\
\hline Colombia & High & High & $0.6^{* *}$ & 0.6 & 0.6 & 0.6 & 0.6 & 0.6 & 0.6 & 0.6 & 0.6 \\
\hline Dominican R. & High & High & 0.4 & 0.4 & $0.4^{*}$ & 0.4 & 0.4 & 0.4 & 0.4 & 0.4 & 0.4 \\
\hline Iceland & High & High & 0.9 & 0.9 & $0.9^{*}$ & 0.9 & 0.9 & 0.9 & 0.9 & 0.9 & 0.9 \\
\hline India & High & High & 0.4 & 0.4 & 0.4 & $0.4 *$ & 0.4 & 0.4 & 0.4 & 0.4 & 0.4 \\
\hline Ireland & High & High & 0.8 & 0.8 & $0.8^{*}$ & 0.8 & 0.8 & 0.8 & 0.8 & 0.8 & 0.8 \\
\hline Peru & High & High & 0.7 & 0.7 & 0.7 & $0.7 *$ & 0.7 & 0.7 & 0.7 & 0.7 & 0.7 \\
\hline South Africa & High & High & 0.4 & 0.4 & $0.4^{*}$ & 0.4 & 0.4 & 0.4 & 0.4 & 0.4 & 0.4 \\
\hline Spain & High & High & 0.6 & $0.6^{*}$ & 0.6 & 0.6 & 0.6 & 0.6 & 0.6 & 0.6 & 0.6 \\
\hline Uruguay & High & High & 0.7 & 0.7 & $0.7 *$ & 0.7 & 0.7 & 0.7 & 0.7 & 0.7 & 0.7 \\
\hline Zambia & High & High & 0.8 & 0.8 & $0.8^{*}$ & 0.8 & 0.8 & 0.8 & 0.8 & 0.8 & 0.8 \\
\hline
\end{tabular}


Table 1 (continued)

\begin{tabular}{|c|c|c|c|c|c|c|c|c|c|c|c|}
\hline \multirow[t]{2}{*}{ Country } & \multirow[t]{2}{*}{ Total external cost } & \multirow[t]{2}{*}{ Gasoline price } & \multicolumn{9}{|c|}{ Benefit-to-cost ratio of rebound $\left(B_{R}\right)$ for a range of elasticities $\left(\varepsilon_{S, P_{S}}\right)$} \\
\hline & & & -0.1 & -0.2 & -0.3 & -0.4 & -0.5 & -0.6 & -0.7 & -0.8 & -0.9 \\
\hline Finland & High & Very high & 0.8 & 0.8 & $0.8^{*}$ & 0.8 & 0.8 & 0.8 & 0.8 & 0.8 & 0.8 \\
\hline France & High & Very high & 0.8 & 0.8 & 0.8 & $0.8^{*}$ & 0.8 & 0.8 & 0.8 & 0.8 & 0.8 \\
\hline Germany & High & Very high & 0.9 & 0.9 & $0.9^{*}$ & 0.9 & 0.9 & 0.9 & 0.9 & 0.9 & 0.9 \\
\hline Greece & High & Very high & 1.1 & 1.1 & $1.1^{*}$ & 1.1 & 1.1 & 1.1 & 1.1 & 1.1 & 1.1 \\
\hline Italy & High & Very high & 1.1 & 1.1 & 1.1 & $1.1^{*}$ & 1.1 & 1.1 & 1.1 & 1.1 & 1.1 \\
\hline Netherlands & High & Very high & 0.9 & 0.9 & $0.9^{*}$ & 0.9 & 0.9 & 0.9 & 0.9 & 0.9 & 0.9 \\
\hline Sweden & High & Very high & 0.8 & 0.8 & $0.8^{*}$ & 0.8 & 0.8 & 0.8 & 0.8 & 0.8 & 0.8 \\
\hline UK & High & Very high & 0.9 & 0.9 & $0.9^{*}$ & 0.9 & 0.9 & 0.9 & 0.9 & 0.9 & 0.9 \\
\hline Japan & Very high & High & 0.3 & $0.3^{*}$ & 0.3 & 0.3 & 0.3 & 0.3 & 0.3 & 0.3 & 0.3 \\
\hline South Korea & Very high & High & 0.4 & 0.4 & 0.4 & 0.4 & 0.4 & $0.4^{*}$ & 0.4 & 0.4 & 0.4 \\
\hline Luxembourg & Very high & High & 0.4 & 0.4 & $0.4^{*}$ & 0.4 & 0.4 & 0.4 & 0.4 & 0.4 & 0.4 \\
\hline Singapore & Very high & High & 0.2 & 0.2 & $0.2^{*}$ & 0.2 & 0.2 & 0.2 & 0.2 & 0.2 & 0.2 \\
\hline Switzerland & Very high & High & 0.4 & 0.4 & 0.4 & $0.4 *$ & 0.4 & 0.4 & 0.4 & 0.4 & 0.4 \\
\hline Belgium & Very high & Very high & 0.6 & 0.6 & $0.6^{*}$ & 0.6 & 0.6 & 0.6 & 0.6 & 0.6 & 0.6 \\
\hline Denmark & Very high & Very high & 0.4 & 0.4 & 0.4 & $0.4 *$ & 0.4 & 0.4 & 0.4 & 0.4 & 0.4 \\
\hline Norway & Very high & Very high & 0.5 & 0.5 & $0.5^{*}$ & 0.5 & 0.5 & 0.5 & 0.5 & 0.5 & 0.5 \\
\hline Turkey & Very high & Very high & 0.7 & $0.7 *$ & 0.7 & 0.7 & 0.7 & 0.7 & 0.7 & 0.7 & 0.7 \\
\hline
\end{tabular}

The overall welfare implications of a free energy efficiency improvement

With our estimates of the benefits and costs of the direct rebound effect in hand, we are now able to assess the overall welfare implications of a costless, exogenous energy efficiency improvement, where the term 'overall' denotes that the direct rebound effect is accounted for.

As previously demonstrated, a free energy efficiency improvement will always be welfare enhancing with zero rebound. But what happens when rebound occurs? Table 2 presents the overall welfare implications of a free $10 \%$ improvement in the energy efficiency of passenger cars, accounting for the costs and benefits of the direct rebound effect. The welfare results demonstrate that in most cases, a free energy efficiency improvement will continue to be welfare enhancing, even when accounting for the negative impact on welfare due to the direct rebound effect. There are however a few countries where a free energy efficiency improvement becomes welfare reducing because of the direct rebound effect. This occurs because these countries had direct rebound effects that were welfare reducing to a degree that overturned the welfare enhancement initially generated by the energy efficiency improvement. As discussed previously, the countries that exhibited the worst direct rebound effects shared characteristics such as low gasoline prices, medium to high congestion costs, and/or medium to high accident costs.

The elasticities play an important role in determining the welfare outcomes of energy efficiency. In general, higher elasticities reduce the net benefits of energy efficiency for two reasons: First, they imply larger direct rebound effects, which in turn have a bigger impact on energy efficiency. Second, at higher elasticities, all benefits that stem from energy savings decrease as the rebound effect grows, turning negative for rebound effects beyond $100 \%$.

Table 2 shows that at an elasticity of -0.1 (that is, at a direct rebound effect of $10 \%$ ), a free energy efficiency improvement is welfare enhancing in all 100 countries. At $10 \%$, the direct rebound effect is too small to have any significant impact. Moving to an elasticity of -0.3 , a free energy efficiency improvement becomes welfare reducing in Singapore 
Table 2 The benefit-to-cost ratio of a free $10 \%$ improvement in the energy efficiency of passenger cars, accounting for the direct rebound effect. The * denotes the welfare results obtained using Dahl's (2012) elasticities

Country Total external cost Gasoline price

Benefit-to-cost ratio of energy efficiency $\left(B_{E E}\right)$ for a range of price elasticities $\left(\varepsilon_{S, P_{S}}\right)$

\begin{tabular}{|c|c|c|c|c|c|c|c|c|c|c|c|}
\hline & & & \\
\hline & & & -0.1 & -0.2 & -0.3 & -0.4 & -0.5 & -0.6 & -0.7 & -0.8 & -0.9 \\
\hline Bahrain & Low & Low & 8.6 & 4.1 & 2.5 & 1.8 & $1.3^{*}$ & 1.0 & 0.8 & 0.7 & 0.5 \\
\hline Brunei & Low & Low & 10.4 & $5.0^{*}$ & 3.3 & 2.4 & 1.8 & 1.5 & 1.2 & 1.0 & 0.9 \\
\hline Egypt & Low & Low & 8.4 & $4.2 *$ & 2.8 & 2.0 & 1.6 & 1.3 & 1.1 & 1.0 & 0.9 \\
\hline Nigeria & Low & Low & 16.5 & $8.1^{*}$ & 5.3 & 3.9 & 3.1 & 2.5 & 2.1 & 1.8 & 1.6 \\
\hline Bolivia & Low & Medium & 11.6 & $5.9^{*}$ & 4.0 & 3.1 & 2.5 & 2.2 & 1.9 & 1.7 & 1.5 \\
\hline Ecuador & Low & Medium & 8.9 & $4.4^{*}$ & 2.9 & 2.2 & 1.7 & 1.5 & 1.2 & 1.1 & 1.0 \\
\hline Ethiopia & Low & Medium & 8.7 & 4.6 & $3.2 *$ & 2.5 & 2.1 & 1.8 & 1.7 & 1.5 & 1.4 \\
\hline Ghana & Low & Medium & 12.9 & 6.7 & $4.7^{*}$ & 3.6 & 3.0 & 2.6 & 2.3 & 2.1 & 1.9 \\
\hline Indonesia & Low & Medium & 10.7 & $5.5^{*}$ & 3.8 & 2.9 & 2.4 & 2.1 & 1.8 & 1.7 & 1.5 \\
\hline Mexico & Low & Medium & 10.2 & 5.3 & $3.7 *$ & 2.8 & 2.4 & 2.0 & 1.8 & 1.6 & 1.5 \\
\hline Pakistan & Low & Medium & 12.6 & 6.6 & 4.6 & $3.5^{*}$ & 2.9 & 2.5 & 2.3 & 2.0 & 1.9 \\
\hline Sudan & Low & Medium & 39.7 & 20.1 & $13.5^{*}$ & 10.3 & 8.3 & 7.0 & 6.1 & 5.4 & 4.8 \\
\hline Vietnam & Low & Medium & 8.4 & 4.4 & $3.1 *$ & 2.4 & 2.0 & 1.7 & 1.5 & 1.4 & 1.3 \\
\hline Bangladesh & Low & High & $9.7 *$ & 5.2 & 3.7 & 2.9 & 2.5 & 2.2 & 2.0 & 1.8 & 1.7 \\
\hline Belarus & Low & High & 9.8 & 5.3 & $3.7 *$ & 3.0 & 2.5 & 2.2 & 2.0 & 1.8 & 1.7 \\
\hline Benin & Low & High & 24.2 & 13.0 & $9.3^{*}$ & 7.4 & 6.3 & 5.5 & 5.0 & 4.6 & 4.3 \\
\hline Bosnia & Low & High & 9.5 & 5.4 & $4.0 *$ & 3.3 & 2.8 & 2.6 & 2.4 & 2.2 & 2.1 \\
\hline Brazil & Low & High & 8.7 & 4.9 & $3.7^{*}$ & 3.1 & 2.7 & 2.4 & 2.3 & 2.1 & 2.0 \\
\hline Cameroon & Low & High & 29.8 & 16.3 & $11.8^{*}$ & 9.5 & 8.2 & 7.3 & 6.6 & 6.2 & 5.8 \\
\hline Estonia & Low & High & 19.1 & 10.8 & $8.1^{*}$ & 6.7 & 5.9 & 5.3 & 4.9 & 4.6 & 4.4 \\
\hline Georgia & Low & High & 11.4 & 6.1 & $4.4^{*}$ & 3.5 & 3.0 & 2.6 & 2.4 & 2.2 & 2.0 \\
\hline Honduras & Low & High & 8.4 & 4.5 & $3.2 *$ & 2.5 & 2.2 & 1.9 & 1.7 & 1.6 & 1.5 \\
\hline Ivory Coast & Low & High & $9.7 *$ & 5.6 & 4.2 & 3.5 & 3.1 & 2.8 & 2.6 & 2.5 & 2.4 \\
\hline Jordan & Low & High & 9.4 & 5.1 & $3.6^{*}$ & 2.9 & 2.4 & 2.1 & 1.9 & 1.8 & 1.7 \\
\hline Mozambique & Low & High & 8.2 & 4.4 & $3.2 *$ & 2.6 & 2.2 & 1.9 & 1.8 & 1.6 & 1.5 \\
\hline Nicaragua & Low & High & 8.5 & 4.6 & $3.3^{*}$ & 2.6 & 2.2 & 2.0 & 1.8 & 1.6 & 1.5 \\
\hline Philippines & Low & High & 13.1 & 7.0 & 5.0 & $4.0^{*}$ & 3.3 & 2.9 & 2.7 & 2.4 & 2.3 \\
\hline Senegal & Low & High & 22.5 & 12.8 & $9.6^{*}$ & 8.0 & 7.0 & 6.4 & 5.9 & 5.6 & 5.3 \\
\hline Slovenia & Low & High & 9.0 & 5.2 & $3.9 *$ & 3.3 & 2.9 & 2.6 & 2.4 & 2.3 & 2.2 \\
\hline Thailand & Low & High & 8.5 & $4.7 *$ & 3.5 & 2.9 & 2.5 & 2.2 & 2.1 & 1.9 & 1.8 \\
\hline Togo & Low & High & 21.3 & 11.6 & $8.4^{*}$ & 6.8 & 5.8 & 5.2 & 4.7 & 4.4 & 4.1 \\
\hline Ukraine & Low & High & $10.2 *$ & 5.4 & 3.8 & 3.0 & 2.6 & 2.3 & 2.0 & 1.9 & 1.7 \\
\hline Zimbabwe & Low & High & 19.3 & $10.7^{*}$ & 7.8 & 6.4 & 5.5 & 4.9 & 4.5 & 4.2 & 4.0 \\
\hline Iran & Medium & Low & 4.8 & $2.2 *$ & 1.4 & 0.9 & 0.7 & 0.5 & 0.4 & 0.3 & 0.2 \\
\hline Oman & Medium & Low & 5.8 & 2.8 & 1.8 & 1.3 & $1.0^{*}$ & 0.8 & 0.6 & 0.5 & 0.5 \\
\hline Saudi Arabia & Medium & Low & $5.5^{*}$ & 2.6 & 1.6 & 1.1 & 0.8 & 0.6 & 0.5 & 0.4 & 0.3 \\
\hline Venezuela & Medium & Low & $5.4^{*}$ & 2.5 & 1.5 & 1.0 & 0.7 & 0.5 & 0.4 & 0.3 & 0.2 \\
\hline Azerbaijan & Medium & Medium & 6.4 & $3.3 *$ & 2.2 & 1.7 & 1.4 & 1.2 & 1.1 & 0.9 & 0.9 \\
\hline Botswana & Medium & Medium & 6.2 & 3.3 & $2.3^{*}$ & 1.8 & 1.5 & 1.3 & 1.2 & 1.1 & 1.0 \\
\hline El Salvador & Medium & Medium & 6.3 & 3.3 & $2.3 *$ & 1.8 & 1.5 & 1.3 & 1.2 & 1.1 & 1.0 \\
\hline Kazakhstan & Medium & Medium & 7.6 & 3.9 & $2.6^{*}$ & 2.0 & 1.6 & 1.4 & 1.2 & 1.1 & 1.0 \\
\hline
\end{tabular}


Table 2 (continued)

Country Total external cost Gasoline price

Benefit-to-cost ratio of energy efficiency $\left(B_{E E}\right)$ for a range of price elasticities $\left(\varepsilon_{S, P_{S}}\right)$

\begin{tabular}{|c|c|c|c|c|c|c|c|c|c|c|c|}
\hline & & & \\
\hline & & & -0.1 & -0.2 & -0.3 & -0.4 & -0.5 & -0.6 & -0.7 & -0.8 & -0.9 \\
\hline Malaysia & Medium & Medium & $5.7 *$ & 2.9 & 1.9 & 1.5 & 1.2 & 1.0 & 0.8 & 0.7 & 0.7 \\
\hline Tunisia & Medium & Medium & 6.1 & $3.2 *$ & 2.3 & 1.8 & 1.5 & 1.3 & 1.2 & 1.1 & 1.0 \\
\hline United States & Medium & Medium & 6.7 & 3.4 & $2.4 *$ & 1.8 & 1.5 & 1.3 & 1.1 & 1.0 & 0.9 \\
\hline Albania & Medium & High & 6.5 & 3.7 & $2.7 *$ & 2.2 & 2.0 & 1.8 & 1.6 & 1.5 & 1.5 \\
\hline Bulgaria & Medium & High & 6.9 & 3.9 & $2.9^{*}$ & 2.4 & 2.1 & 1.9 & 1.8 & 1.7 & 1.6 \\
\hline Chile & Medium & High & 6.1 & 3.4 & $2.5^{*}$ & 2.0 & 1.7 & 1.6 & 1.4 & 1.3 & 1.3 \\
\hline China, P.R. & Medium & High & 6.0 & 3.2 & $2.3 *$ & 1.8 & 1.5 & 1.4 & 1.2 & 1.1 & 1.1 \\
\hline Costa Rica & Medium & High & 6.4 & 3.4 & 2.5 & $2.0^{*}$ & 1.7 & 1.5 & 1.4 & 1.3 & 1.2 \\
\hline Croatia & Medium & High & 7.6 & 4.3 & 3.3 & $2.7 *$ & 2.4 & 2.2 & 2.0 & 1.9 & 1.8 \\
\hline Cyprus & Medium & High & 7.0 & 3.9 & 2.9 & $2.4^{*}$ & 2.1 & 1.9 & 1.8 & 1.7 & 1.6 \\
\hline Czech R. & Medium & High & 5.9 & 3.4 & 2.6 & $2.2 *$ & 1.9 & 1.8 & 1.7 & 1.6 & 1.5 \\
\hline Hungary & Medium & High & 7.3 & 4.2 & 3.2 & $2.7 *$ & 2.4 & 2.1 & 2.0 & 1.9 & 1.8 \\
\hline Kenya & Medium & High & 7.6 & 4.2 & $3.1 *$ & 2.5 & 2.2 & 2.0 & 1.8 & 1.7 & 1.6 \\
\hline Latvia & Medium & High & 8.4 & 4.7 & $3.5^{*}$ & 2.9 & 2.5 & 2.3 & 2.1 & 2.0 & 1.9 \\
\hline Lithuania & Medium & High & 6.2 & 3.5 & $2.6^{*}$ & 2.2 & 1.9 & 1.7 & 1.6 & 1.5 & 1.4 \\
\hline Malta & Medium & High & 6.1 & 3.5 & $2.7^{*}$ & 2.2 & 2.0 & 1.8 & 1.7 & 1.6 & 1.5 \\
\hline Mongolia & Medium & High & 7.7 & 4.2 & $3.0 *$ & 2.4 & 2.0 & 1.8 & 1.6 & 1.5 & 1.4 \\
\hline New Zealand & Medium & High & $6.7 *$ & 3.8 & 2.8 & 2.3 & 2.0 & 1.8 & 1.7 & 1.6 & 1.5 \\
\hline Paraguay & Medium & High & 6.1 & $3.4 *$ & 2.5 & 2.0 & 1.7 & 1.5 & 1.4 & 1.3 & 1.2 \\
\hline Poland & Medium & High & 6.1 & 3.5 & $2.6^{*}$ & 2.2 & 1.9 & 1.7 & 1.6 & 1.5 & 1.4 \\
\hline Romania & Medium & High & 6.0 & 3.4 & $2.5^{*}$ & 2.1 & 1.8 & 1.6 & 1.5 & 1.4 & 1.3 \\
\hline Slovakia & Medium & High & 7.0 & 4.0 & $3.0 *$ & 2.6 & 2.3 & 2.1 & 1.9 & 1.8 & 1.7 \\
\hline Sri Lanka & Medium & High & 5.9 & 3.2 & 2.3 & $1.9 *$ & 1.6 & 1.4 & 1.3 & 1.2 & 1.1 \\
\hline Israel & Medium & Very high & 6.7 & $3.9^{*}$ & 3.0 & 2.5 & 2.2 & 2.0 & 1.9 & 1.8 & 1.7 \\
\hline Portugal & Medium & Very high & 6.1 & 3.6 & $2.8^{*}$ & 2.3 & 2.1 & 1.9 & 1.8 & 1.7 & 1.6 \\
\hline Kuwait & High & Low & $3.8^{*}$ & 1.8 & 1.1 & 0.8 & 0.6 & 0.5 & 0.4 & 0.3 & 0.3 \\
\hline Russia & High & Medium & $6.6^{*}$ & 3.4 & 2.3 & 1.8 & 1.5 & 1.2 & 1.1 & 1.0 & 0.9 \\
\hline Syria & High & Medium & 3.6 & $1.9 *$ & 1.3 & 1.1 & 0.9 & 0.8 & 0.7 & 0.6 & 0.6 \\
\hline Australia & High & High & 5.1 & 2.8 & $2.0^{*}$ & 1.7 & 1.4 & 1.3 & 1.2 & 1.1 & 1.0 \\
\hline Austria & High & High & 5.2 & 3.0 & 2.2 & 1.9 & $1.6^{*}$ & 1.5 & 1.4 & 1.3 & 1.2 \\
\hline Cambodia & High & High & 5.1 & 2.7 & $2.0^{*}$ & 1.6 & 1.3 & 1.2 & 1.1 & 1.0 & 0.9 \\
\hline Canada & High & High & 5.0 & 2.7 & 2.0 & 1.6 & $1.4^{*}$ & 1.2 & 1.1 & 1.0 & 1.0 \\
\hline Colombia & High & High & $5.3 * *$ & 2.9 & 2.2 & 1.8 & 1.5 & 1.4 & 1.3 & 1.2 & 1.1 \\
\hline Dominican R. & High & High & 3.7 & 2.0 & $1.5^{*}$ & 1.2 & 1.0 & 0.9 & 0.8 & 0.8 & 0.7 \\
\hline Iceland & High & High & 5.3 & 3.1 & $2.3 *$ & 2.0 & 1.7 & 1.6 & 1.5 & 1.4 & 1.3 \\
\hline India & High & High & 4.8 & 2.6 & 1.9 & $1.5^{*}$ & 1.3 & 1.1 & 1.0 & 0.9 & 0.9 \\
\hline Ireland & High & High & 4.6 & 2.7 & $2.0^{*}$ & 1.7 & 1.5 & 1.4 & 1.3 & 1.2 & 1.2 \\
\hline Peru & High & High & 5.8 & 3.2 & 2.4 & $1.9 *$ & 1.7 & 1.5 & 1.4 & 1.3 & 1.2 \\
\hline South Africa & High & High & 3.9 & 2.1 & $1.5^{*}$ & 1.2 & 1.1 & 0.9 & 0.9 & 0.8 & 0.7 \\
\hline Spain & High & High & 4.4 & $2.5^{*}$ & 1.9 & 1.6 & 1.4 & 1.2 & 1.1 & 1.1 & 1.0 \\
\hline Uruguay & High & High & 5.6 & 3.2 & $2.3^{*}$ & 1.9 & 1.7 & 1.5 & 1.4 & 1.3 & 1.3 \\
\hline Zambia & High & High & 5.4 & 3.1 & $2.3^{*}$ & 2.0 & 1.7 & 1.6 & 1.5 & 1.4 & 1.3 \\
\hline
\end{tabular}


Table 2 (continued)

\begin{tabular}{|c|c|c|c|c|c|c|c|c|c|c|c|}
\hline \multirow[t]{2}{*}{ Country } & \multirow[t]{2}{*}{ Total external cost } & \multirow[t]{2}{*}{ Gasoline price } & \multicolumn{9}{|c|}{ Benefit-to-cost ratio of energy efficiency $\left(B_{E E}\right)$ for a range of price elasticities $\left(\varepsilon_{S, P_{S}}\right)$} \\
\hline & & & -0.1 & -0.2 & -0.3 & -0.4 & -0.5 & -0.6 & -0.7 & -0.8 & -0.9 \\
\hline Finland & High & Very high & 4.6 & 2.7 & $2.1 *$ & 1.8 & 1.6 & 1.5 & 1.4 & 1.3 & 1.2 \\
\hline France & High & Very high & 4.1 & 2.4 & 1.9 & $1.6^{*}$ & 1.4 & 1.3 & 1.2 & 1.2 & 1.1 \\
\hline Germany & High & Very high & 5.2 & 3.0 & $2.3^{*}$ & 2.0 & 1.8 & 1.6 & 1.5 & 1.4 & 1.4 \\
\hline Greece & High & Very high & 5.4 & 3.2 & $2.5^{*}$ & 2.1 & 1.9 & 1.8 & 1.7 & 1.6 & 1.5 \\
\hline Italy & High & Very high & 6.0 & 3.5 & 2.7 & $2.3 *$ & 2.0 & 1.9 & 1.7 & 1.7 & 1.6 \\
\hline Netherlands & High & Very high & 4.2 & 2.5 & $2.0 *$ & 1.7 & 1.5 & 1.4 & 1.3 & 1.3 & 1.2 \\
\hline Sweden & High & Very high & 4.4 & 2.6 & $2.0^{*}$ & 1.7 & 1.5 & 1.4 & 1.3 & 1.2 & 1.2 \\
\hline UK & High & Very high & 4.7 & 2.8 & $2.1^{*}$ & 1.8 & 1.6 & 1.5 & 1.4 & 1.3 & 1.3 \\
\hline Japan & Very high & High & 2.5 & $1.4 *$ & 1.1 & 0.9 & 0.8 & 0.7 & 0.6 & 0.6 & 0.6 \\
\hline South Korea & Very high & High & 3.3 & 1.8 & 1.4 & 1.1 & 1.0 & $0.9^{*}$ & 0.8 & 0.8 & 0.7 \\
\hline Luxembourg & Very high & High & 2.9 & 1.7 & $1.2^{*}$ & 1.0 & 0.9 & 0.8 & 0.8 & 0.7 & 0.7 \\
\hline Singapore & Very high & High & 2.2 & 1.2 & $0.9 *$ & 0.7 & 0.6 & 0.6 & 0.5 & 0.5 & 0.4 \\
\hline Switzerland & Very high & High & 2.8 & 1.6 & 1.2 & $1.0^{*}$ & 0.9 & 0.8 & 0.8 & 0.7 & 0.7 \\
\hline Belgium & Very high & Very high & 3.6 & 2.1 & $1.6^{*}$ & 1.4 & 1.2 & 1.1 & 1.0 & 1.0 & 0.9 \\
\hline Denmark & Very high & Very high & 2.1 & 1.2 & 1.0 & $0.8^{*}$ & 0.7 & 0.7 & 0.6 & 0.6 & 0.6 \\
\hline Norway & Very high & Very high & 2.7 & 1.6 & $1.3^{*}$ & 1.1 & 1.0 & 0.9 & 0.9 & 0.8 & 0.8 \\
\hline Turkey & Very high & Very high & 2.8 & $1.7^{*}$ & 1.4 & 1.2 & 1.1 & 1.0 & 1.0 & 0.9 & 0.9 \\
\hline
\end{tabular}

and Denmark, the two countries with the highest congestion costs among the 100 countries (IMF
2016). At an elasticity of -0.4 , Iran and Venezuela join Singapore and Denmark, although different

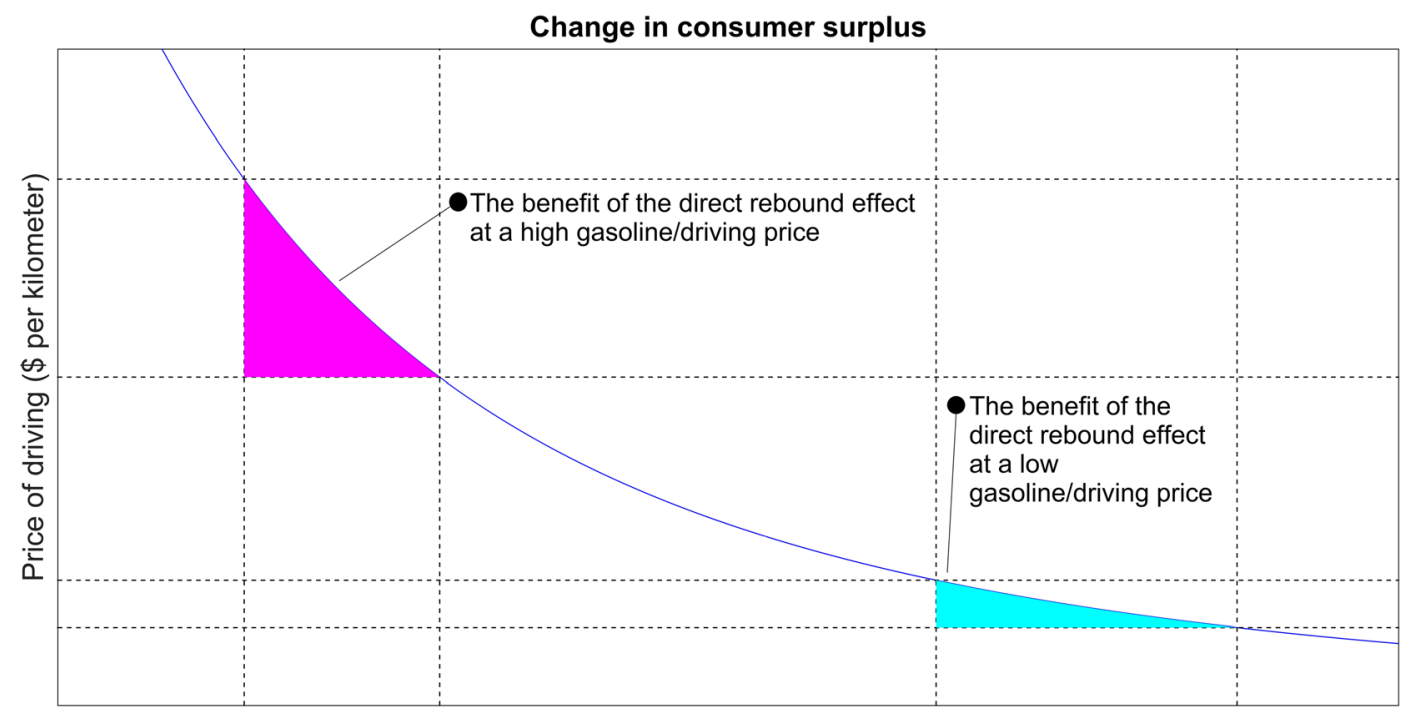

Vehicle kilometers travelled

Fig. 2 The consumer surplus gained from additional driving $\left(B_{R}\right)$ at high and low prices following the same fixed percentage improvement in energy efficiency 
factors play a role. Both Iran and Venezuela enjoyed the lowest gasoline prices and had "medium" accident and congestion costs. At an elasticity of -0.6 , the group of countries in which a free energy efficiency improvement was found to be welfare reducing grows to 16 . At an elasticity of -0.9 (that is, at a direct rebound effect of 90\%), a free energy efficiency improvement was found to be welfare reducing in every country with "very high external costs", which includes Japan, South Korea, Luxembourg, Singapore, Switzerland, Belgium, Denmark, Norway, and Turkey, in addition to a number of other countries.

In summary, the more price elastic the demand for driving, the larger the direct rebound effect. The larger the direct rebound effect, the more significant its impact on the cost-benefit evaluation of energy efficiency. When direct rebound effects are large, countries with very low gasoline prices and/or high external costs will likely find a free energy efficiency improvement in passenger cars to be welfare reducing.

How would the results change if the upfront capital costs of an energy efficiency improvement were accounted for? For countries where a free energy efficiency improvement was found to be welfare reducing, the welfare outcomes would not change. For example, at a direct rebound effect of $30 \%$, an energy efficiency improvement in passenger cars would be welfare reducing in Singapore and Denmark (see Table 2). If we included the capital costs, then the welfare reduction would be even greater. However, the assessment that the improvement is welfare reducing in both countries does not change by accounting for the capital costs-it simply makes the improvement more welfare reducing. On the other hand, for countries where a free energy efficiency improvement is welfare enhancing, accounting for the capital costs may potentially overturn the result. If the benefit-to-cost ratio is only slightly greater that one, then it is very likely that accounting for the upfront costs, even if small, would overturn the result and produce a welfare reduction (that is, a benefit-to-cost ratio less than one).

On a final note, when there is an upfront cost to the energy efficiency improvement, the boost to income from improved energy efficiency becomes smaller, as discussed by Borenstein (2015). As a result, the income effect that contributes to rebound becomes weaker, leading to smaller rebound effects.

\section{Conclusion}

This paper is, to the best of our knowledge, the first to conduct a global empirical welfare analysis of the direct rebound effect. It also demonstrates empirically the extent of the impact that the direct rebound effect can have on the welfare outcomes of energy efficiency.

Our results reveal the direct rebound effect in driving to be welfare reducing in most countries. Because of high externalities, the costs of rebound are often found to exceed the benefits. Furthermore, we found that the direct rebound effect is generally worse (that is, more welfare reducing) in countries with some combination of low gasoline prices and medium to high congestion and accident costs.

The results carry important implications for energy efficiency policymaking given that most evaluations of energy efficiency do not account for the costs and benefits of rebound, which can produce a misleading picture of energy efficiency. In fact, in countries with the most welfare reducing direct rebound effects, we demonstrate that even a free energy efficiency improvement in passenger cars can become welfare reducing when accounting for rebound.

Our work has three key messages for policymakers. First, it highlights the importance of accounting for the rebound effect, which can have a considerable impact on cost-benefit analyses of energy efficiency policies. Policymakers should therefore be skeptical about any assessments of energy efficiency that do not include the costs and benefits of rebound.

Second, energy efficiency policies such as fuel economy standards are less likely to be welfare enhancing when the external costs of congestion and accidents are high, because rebound effects lead to higher levels of congestion and accidents. Energy efficiency policies for passenger cars may thus find greater success when combined with complementary policies that can mitigate congestion and reduce road accidents, such as better public transport to reduce congestion and speed enforcement cameras to reduce accidents (Tang 2017). 
The third key message is that the rebound effect is not always welfare reducing, as some studies have suggested. The direct rebound effect from more efficient cars was found to be welfare enhancing in some cases. Furthermore, the direct rebound effect in other energy services (such as lighting and cooling) where total external costs are smaller appears likely to be welfare enhancing. More work in this area could help change the negative perceptions that the rebound effect holds in energy policy discussions. Moreover, if energy prices were increased (through taxes for example) such that all negative externalities are incorporated into the price, then any subsequent rebound effects would always be welfare enhancing, as noted by Azevedo (2014). By getting energy prices right, policymakers would not need to worry about rebound since it would only improve social welfare.

Ultimately, the primary goal of energy efficiency is to maximize welfare rather minimize energy consumption, and the rebound effect may help support that goal. The results presented in this paper could help inform the "heated" debate around energy efficiency, which revolves around a number of key questions including the rebound effect (Brown and Wang 2017).

There remains huge scope for empirical research on the area of rebound and social welfare. The analysis presented in this paper focused on consumers and the government. We effectively assumed a market structure of perfect competition such that producer surplus falls to zero. Furthermore, the analysis did not consider the welfare implications of the indirect and economy-wide rebound effects. Future work could account for these factors, providing an even more complete picture of the welfare implications of energy efficiency and rebound. Future work could also examine rebound in other energy services, such as heating, cooling, and lighting. Future work would also benefit from the provision of more recent estimates for the external costs of energy consumption on a country-by-country basis, which is often the limiting factor in such studies. This will allow researchers to conduct cost-benefit analyses with more recent data, delivering insights that are more relevant and practical to policymakers.

Acknowledgments We are grateful to Nicholas Chase, Marcello Contestabile, Rubal Dua, Rolando Fuentes, Lester Hunt, and Axel Pierru for their helpful feedback. We are also grateful to the anonymous reviewers for their insightful comments and suggestions.
Nonetheless, we are of course responsible for all errors and omissions. The views expressed in this paper are those of the authors and do not necessarily represent the views of their affiliated institutions. Finally, this research did not receive any specific grant from funding agencies in the public, commercial, or not-forprofit sectors.

\section{Compliance with ethical standards}

Conflict of interest The authors declare that they have no conflict of interest.

\section{Appendix 1}

\section{An example}

The methods are best illustrated through an example. In the case of Saudi Arabia, gasoline demand in 2010 totalled roughly 24,165,966,000 liters (IEA 2016a), while the average fuel economy of the total stock of passenger cars was 8.387 kilometers per liter. Multiplying gasoline consumption by the average fuel economy yields the total demand for driving in gasoline-vehicles in Saudi Arabia in 2010:

$$
\begin{aligned}
S_{0} & =\eta E_{0}=8.387 * 24,165,966,000 \\
& =202,679,956,842 v k t
\end{aligned}
$$

According to the World Bank (2016), the price of gasoline in Saudi Arabia in 2010 was 16.0 cents per liter. The implicit price of driving was then calculated to be $\frac{16.0}{8.387}=1.908$ cents per kilometer in that year.

Given the total demand for driving and the implicit price of driving, the scale parameter can be calibrated. This however requires an assumption on the size of the elasticity $\varepsilon_{S, P_{S}}$, also denoted by $\beta$, which reflects the size of the direct rebound effect. According to Dahl (2012), the gasoline price elasticity in Saudi Arabia is $\varepsilon_{E, P_{E}}=-0.1$. If the Saudi road sector is described as single-energy single-service, then $\varepsilon_{S, P_{S}}=\varepsilon_{E, P_{E}}=-0.1$. Therefore,

$$
\begin{aligned}
K & =\frac{S_{0}}{P_{S, B}{ }^{\beta}}=\frac{202,679,956,842}{1.908^{-0.1}} \\
& =216,206,447,130
\end{aligned}
$$

\section{Calculating the benefits}

If a $10 \%$ improvement in energy efficiency occurred, the implicit price of driving would fall to $\frac{16.0}{9.226}=1.734$ 
cents per kilometer. We can then calculate the total surplus gained by consumers because of this $10 \%$ improvement:

$$
\begin{aligned}
B_{C S} & =\frac{K}{\beta+1}^{*}\left[P_{S, B}{ }^{\beta+1}-P_{S, A}^{\beta+1}\right] \\
& =\frac{216,206,447,130^{*}}{0.9}\left(1.908^{0.9}-1.734^{0.9}\right) \\
& =354,327,680
\end{aligned}
$$

Part of this gain is due to the monetary savings:

$$
\begin{aligned}
B_{M S} & =\left(P_{S, B}-P_{S, A}\right) * S_{0} \\
& =(1.908-1.734) * 202,679,956,842 \\
& =352,663,125
\end{aligned}
$$

The other part is due to the direct rebound effect:

$$
\begin{aligned}
B_{R} & =B_{C S}-B_{M S} \\
& =(354,327,680-352,663,125)=1,664,555
\end{aligned}
$$

Thus, the consumer surplus gained from the direct rebound effect would have been about half a percent of the total gain in consumer surplus. This is not surprising given that the elasticity in this example was small. For larger elasticities, the portion of consumer surplus gained from rebound rises considerably.

The final benefit of improved energy efficiency stems from the reduction in external costs through reduced gasoline demand, assuming no rebound. The IMF (2016) data shows that the external costs of GHG emissions and air pollution associated with each liter of gasoline consumption in Saudi Arabia were 8.3 and 2.5 cents per liter, respectively ( $\delta_{E}=10.8$ cents per liter). Assuming no rebound, a $10 \%$ improvement in energy efficiency would have reduced gasoline demand in Saudi Arabia to $\frac{24,165,966,000}{(1+10 \%)}=21,969,060,000$ liters. Thus,

$$
\begin{aligned}
B_{E C} & =\left(E_{0}-E_{N R}\right) * \delta_{E} \\
& =(24,165,966,000-21,969,060,000) * 10.8 \\
& =237,265,848
\end{aligned}
$$

In summary, a $10 \%$ improvement in the energy efficiency of gasoline-based cars in Saudi Arabia would have yielded a total benefit of:
$B_{E E}=B_{M S}+B_{R}+B_{E C}=591,593,528$

\section{Calculating the costs}

When rebound occurs, both the demand for gasoline and driving increase. With an elasticity of $\beta=-0.1$, the rebound effect would cause the demand for driving to rise from $202,679,956,842$ to:

$$
\begin{aligned}
S_{R} & =K P_{S, A}{ }^{-0.1}=216,206,447,130 * 1.734^{-0.1} \\
& =204,627,373,960 v k t
\end{aligned}
$$

The gasoline consumption associated with this new level of driving is obtained as follows:

$$
\begin{aligned}
E_{R} & =\frac{S_{R}}{\eta^{*}(1+10 \%)}=\frac{204,627,373,960}{8.387 * 1.1} \\
& =22,180,146,109 \text { liters }
\end{aligned}
$$

According to the IMF (2016), the external costs of air pollution and GHG emissions are $\delta_{E}=10.8$. The increase in energy-related external costs can thus be calculated as follows:

$$
\begin{aligned}
C_{E} & =\left(E_{R}-E_{N R}\right) * \delta_{E} \\
& =(22,180,146,109-21,969,060,000) * 10.8 \\
& =22,797,300
\end{aligned}
$$

According to the IMF (2016), the external costs of congestion and accidents associated with each kilometer of driving in Saudi Arabia were 4.9 and 6.6 cents per kilometer ( $\delta_{S}=11.5$ cents per kilometer). The increase in service-related external costs can thus be calculated as follows:

$$
\begin{aligned}
C_{S} & =\left(S_{R}-S_{0}\right) * \delta_{S} \\
& =(204,627,373,960-202,679,956,842) * 11.5 \\
& =223,952,968
\end{aligned}
$$

The total cost associated with the direct rebound effect is the sum of the energy- and service-related external costs: 
$C_{R}=C_{E}+C_{S}=246,750,268$

Assuming zero capital costs, the total cost of the improvement is equal to the total cost of the direct rebound effect:

$C_{E E}=C_{R}=246,750,268$

At this point, we can produce preliminary estimates of the benefit-to-cost ratio for both the direct rebound effect and the energy efficiency improvement. But these estimates would not account for the impact on the government, which may subsidize or tax gasoline. In the case of Saudi Arabia, an energy efficiency improvement will lead to a net gain for the government so long as the direct rebound effect is less than $100 \%$, since any fall in gasoline consumption will lead to a fall in the implicit subsidy for gasoline. According to Platts (2016), the average international market price for gasoline at Jebel Ali port in 2010 was 54.1 cents per liter, compared to a domestic price of 16.0. Therefore, the total gain to the government because of the $10 \%$ energy efficiency improvement was:

$$
\begin{aligned}
G_{E E} & =\left(P_{E}{ }^{*}-P_{E}\right) *\left(E_{0}-E_{R}\right) \\
& =(54.1-16.0) *(24,165,966,000-22,180,146,109) \\
& =756,597,379
\end{aligned}
$$

It is possible to isolate the part of this gain that is purely due to the direct rebound effect. In the case of Saudi Arabia, the direct rebound effect causes a loss to the government as it increases gasoline consumption above a scenario in which there was no rebound. This loss can be calculated as follows:

$$
\begin{aligned}
G_{R} & =\left(P_{E}{ }^{*}-P_{E}\right) *\left(E_{N R}-E_{R}\right) \\
& =(54.1-16.0) *(21,969,060,000-22,180,146,109) \\
& =-80,423,808
\end{aligned}
$$

The minus sign indicates that the rebound effect leads to a loss for the government.

\section{Benefit-to-cost ratios}

With all the necessary components calculated, we can proceed to estimating the benefit-to-cost ratio for the direct rebound effect,

$$
\begin{aligned}
B C R_{R} & =\frac{B_{R}}{C_{R}-G_{R}} \\
& =\frac{1,664,555}{246,750,268+80,423,808=0.005}(\text { A. } 16)
\end{aligned}
$$

Given that the direct rebound effect leads to a cost for the government, $G_{R}$ is placed in the denominator of Eq. (A.16).

In the case of the energy efficiency improvement,

$$
\begin{aligned}
B C R_{E E} & =\frac{B_{E E}+G_{E E}}{C_{E E}} \\
& =591,593,528+\frac{756,597,379}{246,750,268=5.47}
\end{aligned}
$$

Given that energy efficiency leads to a net gain for the government, $G_{E E}$ is placed in the numerator of Eq. (A.17). Thus, the benefit-to-cost ratio reveals that the benefits of a free energy efficiency improvement are considerably larger than the costs, even when accounting for the negative welfare reduction caused by the direct rebound effect.

\section{Appendix 2}

The potential welfare implications of the direct rebound effect in other energy services

An improvement in the efficiency of lighting or cooling for example would give rise to a rebound effect that generates external costs in air pollution and GHG emissions only (there may be some other minor external costs). We can roughly approximate the potential welfare implications of such an improvement by setting the external costs of congestion and accidents to zero and then re-estimating the benefit-to-cost ratio of the direct rebound effect.

In the case of driving, most of the cost associated with the direct rebound effect is due to congestion and accidents. According to Parry et al. (2014), the average external cost of air pollution and GHG emissions together was 10.7 US cents per liter, while the average external cost of congestion and accidents amounted to 43.5 US cents per liter (both averages taken across all 100 countries for 2010). Service-related externalities thus accounted for over $80 \%$ of the total cost of the direct rebound effect in driving. 
Table 3 The benefit-to-cost ratio of the direct rebound effect following a 10\% energy efficiency improvement, assuming zero servicerelated external costs

\begin{tabular}{|c|c|c|c|c|c|c|c|c|c|c|}
\hline \multirow[t]{2}{*}{ Countries } & \multirow[t]{2}{*}{ Gasoline price } & \multicolumn{9}{|c|}{ Benefit-to-cost ratio of rebound $\left(B_{R}\right)$ for a range of elasticities $\left(\varepsilon_{S, P_{S}}\right)$} \\
\hline & & -0.1 & -0.2 & -0.3 & -0.4 & -0.5 & -0.6 & -0.7 & -0.8 & -0.9 \\
\hline Bahrain & Low & 0.0 & 0.0 & 0.0 & 0.0 & 0.0 & 0.0 & 0.0 & 0.0 & 0.0 \\
\hline Brunei & Low & 0.1 & 0.1 & 0.1 & 0.1 & 0.1 & 0.1 & 0.1 & 0.1 & 0.1 \\
\hline Egypt & Low & 0.2 & 0.2 & 0.2 & 0.2 & 0.2 & 0.2 & 0.2 & 0.2 & 0.2 \\
\hline Iran & Low & 0.0 & 0.0 & 0.0 & 0.0 & 0.0 & 0.0 & 0.0 & 0.0 & 0.0 \\
\hline Kuwait & Low & 0.0 & 0.0 & 0.0 & 0.0 & 0.0 & 0.0 & 0.0 & 0.0 & 0.0 \\
\hline Nigeria & Low & 0.1 & 0.1 & 0.1 & 0.1 & 0.1 & 0.1 & 0.1 & 0.1 & 0.1 \\
\hline Oman & Low & 0.0 & 0.0 & 0.0 & 0.0 & 0.0 & 0.0 & 0.0 & 0.0 & 0.0 \\
\hline Saudi Arabia & Low & 0.0 & 0.0 & 0.0 & 0.0 & 0.0 & 0.0 & 0.0 & 0.0 & 0.0 \\
\hline Venezuela & Low & 0.0 & 0.0 & 0.0 & 0.0 & 0.0 & 0.0 & 0.0 & 0.0 & 0.0 \\
\hline Azerbaijan & Medium & 1.1 & 1.1 & 1.1 & 1.1 & 1.1 & 1.1 & 1.1 & 1.1 & 1.1 \\
\hline Bolivia & Medium & 2.2 & 2.2 & 2.2 & 2.2 & 2.2 & 2.2 & 2.2 & 2.2 & 2.2 \\
\hline Botswana & Medium & 4.2 & 4.2 & 4.2 & 4.2 & 4.2 & 4.2 & 4.2 & 4.2 & 4.2 \\
\hline Ecuador & Medium & 0.2 & 0.2 & 0.2 & 0.2 & 0.2 & 0.2 & 0.2 & 0.2 & 0.2 \\
\hline El Salvador & Medium & 4.7 & 4.7 & 4.7 & 4.7 & 4.7 & 4.7 & 4.7 & 4.7 & 4.7 \\
\hline Ethiopia & Medium & 4.9 & 4.9 & 4.9 & 4.9 & 4.9 & 4.9 & 4.9 & 4.9 & 4.9 \\
\hline Ghana & Medium & 3.7 & 3.7 & 3.7 & 3.7 & 3.7 & 3.7 & 3.7 & 3.7 & 3.7 \\
\hline Indonesia & Medium & 2.6 & 2.6 & 2.6 & 2.6 & 2.6 & 2.6 & 2.6 & 2.6 & 2.6 \\
\hline Kazakhstan & Medium & 1.0 & 1.0 & 1.0 & 1.0 & 1.0 & 1.0 & 1.0 & 1.0 & 1.0 \\
\hline Malaysia & Medium & 0.6 & 0.6 & 0.6 & 0.6 & 0.6 & 0.6 & 0.6 & 0.6 & 0.6 \\
\hline Mexico & Medium & 2.7 & 2.7 & 2.7 & 2.7 & 2.7 & 2.7 & 2.7 & 2.7 & 2.7 \\
\hline Pakistan & Medium & 3.1 & 3.1 & 3.1 & 3.1 & 3.1 & 3.1 & 3.1 & 3.1 & 3.1 \\
\hline Russia & Medium & 0.6 & 0.6 & 0.6 & 0.6 & 0.6 & 0.6 & 0.6 & 0.6 & 0.6 \\
\hline Sudan & Medium & 1.3 & 1.3 & 1.3 & 1.3 & 1.3 & 1.3 & 1.3 & 1.3 & 1.3 \\
\hline Syria & Medium & 5.1 & 5.1 & 5.1 & 5.1 & 5.1 & 5.1 & 5.1 & 5.1 & 5.1 \\
\hline Tunisia & Medium & 3.6 & 3.6 & 3.6 & 3.6 & 3.6 & 3.6 & 3.6 & 3.6 & 3.6 \\
\hline United States & Medium & 2.3 & 2.3 & 2.3 & 2.3 & 2.3 & 2.3 & 2.3 & 2.3 & 2.3 \\
\hline Vietnam & Medium & 2.7 & 2.7 & 2.7 & 2.7 & 2.7 & 2.7 & 2.7 & 2.7 & 2.7 \\
\hline Albania & High & 11.1 & 11.1 & 11.1 & 11.1 & 11.1 & 11.1 & 11.1 & 11.1 & 11.1 \\
\hline Australia & High & 7.8 & 7.8 & 7.8 & 7.8 & 7.8 & 7.8 & 7.8 & 7.8 & 7.8 \\
\hline Austria & High & 12.8 & 12.8 & 12.8 & 12.8 & 12.8 & 12.8 & 12.8 & 12.8 & 12.8 \\
\hline Bangladesh & High & 3.9 & 3.9 & 3.9 & 3.9 & 3.9 & 3.9 & 3.9 & 3.9 & 3.9 \\
\hline Belarus & High & 3.4 & 3.4 & 3.4 & 3.4 & 3.4 & 3.4 & 3.4 & 3.4 & 3.4 \\
\hline Benin & High & 6.5 & 6.5 & 6.5 & 6.5 & 6.5 & 6.5 & 6.5 & 6.5 & 6.5 \\
\hline Bosnia & High & 10.5 & 10.5 & 10.5 & 10.5 & 10.5 & 10.5 & 10.5 & 10.5 & 10.5 \\
\hline Brazil & High & 10.7 & 10.7 & 10.7 & 10.7 & 10.7 & 10.7 & 10.7 & 10.7 & 10.7 \\
\hline Bulgaria & High & 11.1 & 11.1 & 11.1 & 11.1 & 11.1 & 11.1 & 11.1 & 11.1 & 11.1 \\
\hline Cambodia & High & 6.2 & 6.2 & 6.2 & 6.2 & 6.2 & 6.2 & 6.2 & 6.2 & 6.2 \\
\hline Cameroon & High & 7.5 & 7.5 & 7.5 & 7.5 & 7.5 & 7.5 & 7.5 & 7.5 & 7.5 \\
\hline Canada & High & 6.8 & 6.8 & 6.8 & 6.8 & 6.8 & 6.8 & 6.8 & 6.8 & 6.8 \\
\hline Chile & High & 7.2 & 7.2 & 7.2 & 7.2 & 7.2 & 7.2 & 7.2 & 7.2 & 7.2 \\
\hline China, P.R. & High & 5.0 & 5.0 & 5.0 & 5.0 & 5.0 & 5.0 & 5.0 & 5.0 & 5.0 \\
\hline
\end{tabular}


Table 3 (continued)

\begin{tabular}{|c|c|c|c|c|c|c|c|c|c|c|}
\hline \multirow[t]{2}{*}{ Countries } & \multirow[t]{2}{*}{ Gasoline price } & \multicolumn{9}{|c|}{ Benefit-to-cost ratio of rebound $\left(B_{R}\right)$ for a range of elasticities $\left(\varepsilon_{S, P_{S}}\right)$} \\
\hline & & -0.1 & -0.2 & -0.3 & -0.4 & -0.5 & -0.6 & -0.7 & -0.8 & -0.9 \\
\hline Colombia & High & 7.3 & 7.3 & 7.3 & 7.3 & 7.3 & 7.3 & 7.3 & 7.3 & 7.3 \\
\hline Costa Rica & High & 6.5 & 6.5 & 6.5 & 6.5 & 6.5 & 6.5 & 6.5 & 6.5 & 6.5 \\
\hline Croatia & High & 12.0 & 12.0 & 12.0 & 12.0 & 12.0 & 12.0 & 12.0 & 12.0 & 12.0 \\
\hline Cyprus & High & 11.9 & 11.9 & 11.9 & 11.9 & 11.9 & 11.9 & 11.9 & 11.9 & 11.9 \\
\hline Czech R. & High & 13.8 & 13.8 & 13.8 & 13.8 & 13.8 & 13.8 & 13.8 & 13.8 & 13.8 \\
\hline Dominican R. & High & 6.9 & 6.9 & 6.9 & 6.9 & 6.9 & 6.9 & 6.9 & 6.9 & 6.9 \\
\hline Estonia & High & 9.7 & 9.7 & 9.7 & 9.7 & 9.7 & 9.7 & 9.7 & 9.7 & 9.7 \\
\hline Georgia & High & 3.4 & 3.4 & 3.4 & 3.4 & 3.4 & 3.4 & 3.4 & 3.4 & 3.4 \\
\hline Honduras & High & 6.0 & 6.0 & 6.0 & 6.0 & 6.0 & 6.0 & 6.0 & 6.0 & 6.0 \\
\hline Hungary & High & 12.9 & 12.9 & 12.9 & 12.9 & 12.9 & 12.9 & 12.9 & 12.9 & 12.8 \\
\hline Iceland & High & 14.6 & 14.6 & 14.6 & 14.6 & 14.6 & 14.6 & 14.6 & 14.6 & 14.6 \\
\hline India & High & 5.5 & 5.5 & 5.5 & 5.5 & 5.5 & 5.5 & 5.5 & 5.5 & 5.5 \\
\hline Ireland & High & 15.5 & 15.5 & 15.5 & 15.5 & 15.5 & 15.5 & 15.5 & 15.5 & 15.5 \\
\hline Ivory Coast & High & 13.3 & 13.3 & 13.3 & 13.3 & 13.3 & 13.3 & 13.3 & 13.3 & 13.3 \\
\hline Japan & High & 8.7 & 8.7 & 8.7 & 8.7 & 8.7 & 8.7 & 8.7 & 8.7 & 8.7 \\
\hline Jordan & High & 6.2 & 6.2 & 6.2 & 6.2 & 6.2 & 6.2 & 6.2 & 6.2 & 6.2 \\
\hline Kenya & High & 10.0 & 10.0 & 10.0 & 10.0 & 10.0 & 10.0 & 10.0 & 10.0 & 10.0 \\
\hline Latvia & High & 8.9 & 8.9 & 8.9 & 8.9 & 8.9 & 8.9 & 8.9 & 8.9 & 8.9 \\
\hline Lithuania & High & 8.7 & 8.7 & 8.7 & 8.7 & 8.7 & 8.7 & 8.7 & 8.6 & 8.6 \\
\hline Luxembourg & High & 13.1 & 13.1 & 13.1 & 13.1 & 13.1 & 13.1 & 13.1 & 13.1 & 13.1 \\
\hline Malta & High & 14.1 & 14.1 & 14.1 & 14.1 & 14.1 & 14.1 & 14.1 & 14.1 & 14.1 \\
\hline Mongolia & High & 5.5 & 5.5 & 5.5 & 5.5 & 5.5 & 5.5 & 5.5 & 5.5 & 5.5 \\
\hline Mozambique & High & 7.4 & 7.4 & 7.4 & 7.4 & 7.4 & 7.4 & 7.4 & 7.4 & 7.4 \\
\hline New Zealand & High & 11.9 & 11.9 & 11.9 & 11.8 & 11.8 & 11.8 & 11.8 & 11.8 & 11.8 \\
\hline Nicaragua & High & 7.0 & 7.0 & 7.0 & 7.0 & 7.0 & 7.0 & 7.0 & 7.0 & 7.0 \\
\hline Paraguay & High & 8.9 & 8.9 & 8.9 & 8.9 & 8.9 & 8.9 & 8.9 & 8.9 & 8.9 \\
\hline Peru & High & 9.3 & 9.3 & 9.3 & 9.3 & 9.3 & 9.3 & 9.3 & 9.3 & 9.3 \\
\hline Philippines & High & 5.7 & 5.7 & 5.7 & 5.7 & 5.7 & 5.7 & 5.7 & 5.7 & 5.7 \\
\hline Poland & High & 11.7 & 11.7 & 11.7 & 11.7 & 11.7 & 11.7 & 11.7 & 11.7 & 11.7 \\
\hline Romania & High & 10.7 & 10.7 & 10.7 & 10.7 & 10.7 & 10.7 & 10.7 & 10.7 & 10.7 \\
\hline South Korea & High & 9.8 & 9.8 & 9.8 & 9.8 & 9.8 & 9.8 & 9.8 & 9.8 & 9.8 \\
\hline Senegal & High & 12.8 & 12.8 & 12.8 & 12.8 & 12.8 & 12.8 & 12.8 & 12.8 & 12.8 \\
\hline Singapore & High & 5.5 & 5.5 & 5.5 & 5.5 & 5.5 & 5.5 & 5.5 & 5.5 & 5.5 \\
\hline Slovakia & High & 13.8 & 13.8 & 13.8 & 13.8 & 13.7 & 13.7 & 13.7 & 13.7 & 13.7 \\
\hline Slovenia & High & 13.4 & 13.4 & 13.4 & 13.4 & 13.4 & 13.4 & 13.4 & 13.4 & 13.4 \\
\hline South Africa & High & 7.3 & 7.3 & 7.3 & 7.3 & 7.3 & 7.3 & 7.3 & 7.3 & 7.3 \\
\hline Spain & High & 10.7 & 10.7 & 10.7 & 10.7 & 10.7 & 10.7 & 10.7 & 10.7 & 10.7 \\
\hline Sri Lanka & High & 7.1 & 7.0 & 7.0 & 7.0 & 7.0 & 7.0 & 7.0 & 7.0 & 7.0 \\
\hline Switzerland & High & 13.5 & 13.5 & 13.5 & 13.5 & 13.5 & 13.5 & 13.5 & 13.5 & 13.5 \\
\hline Thailand & High & 10.2 & 10.2 & 10.2 & 10.2 & 10.2 & 10.2 & 10.2 & 10.2 & 10.2 \\
\hline Togo & High & 8.3 & 8.3 & 8.3 & 8.3 & 8.3 & 8.3 & 8.3 & 8.3 & 8.3 \\
\hline Ukraine & High & 4.4 & 4.4 & 4.4 & 4.4 & 4.4 & 4.4 & 4.4 & 4.4 & 4.4 \\
\hline
\end{tabular}


Table 3 (continued)

\begin{tabular}{|c|c|c|c|c|c|c|c|c|c|c|}
\hline \multirow[t]{2}{*}{ Countries } & \multirow[t]{2}{*}{ Gasoline price } & \multicolumn{9}{|c|}{ Benefit-to-cost ratio of rebound $\left(B_{R}\right)$ for a range of elasticities $\left(\varepsilon_{S, P_{S}}\right)$} \\
\hline & & -0.1 & -0.2 & -0.3 & -0.4 & -0.5 & -0.6 & -0.7 & -0.8 & -0.9 \\
\hline Uruguay & High & 10.3 & 10.3 & 10.3 & 10.3 & 10.3 & 10.3 & 10.3 & 10.3 & 10.3 \\
\hline Zambia & High & 14.0 & 14.0 & 14.0 & 14.0 & 14.0 & 14.0 & 14.0 & 14.0 & 14.0 \\
\hline Zimbabwe & High & 9.6 & 9.6 & 9.6 & 9.6 & 9.6 & 9.6 & 9.6 & 9.6 & 9.6 \\
\hline Belgium & Very high & 15.6 & 15.6 & 15.6 & 15.6 & 15.6 & 15.6 & 15.6 & 15.6 & 15.6 \\
\hline Denmark & Very high & 17.9 & 17.9 & 17.9 & 17.9 & 17.9 & 17.9 & 17.9 & 17.8 & 17.8 \\
\hline Finland & Very high & 16.5 & 16.5 & 16.5 & 16.5 & 16.5 & 16.5 & 16.5 & 16.5 & 16.5 \\
\hline France & Very high & 15.5 & 15.5 & 15.5 & 15.5 & 15.5 & 15.5 & 15.5 & 15.5 & 15.5 \\
\hline Germany & Very high & 15.5 & 15.5 & 15.5 & 15.5 & 15.5 & 15.5 & 15.5 & 15.5 & 15.5 \\
\hline Greece & Very high & 17.8 & 17.8 & 17.8 & 17.8 & 17.8 & 17.7 & 17.7 & 17.7 & 17.7 \\
\hline Israel & Very high & 10.4 & 10.3 & 10.3 & 10.3 & 10.3 & 10.3 & 10.3 & 10.3 & 10.3 \\
\hline Italy & Very high & 15.5 & 15.5 & 15.5 & 15.4 & 15.4 & 15.4 & 15.4 & 15.4 & 15.4 \\
\hline Netherlands & Very high & 18.3 & 18.3 & 18.3 & 18.3 & 18.3 & 18.3 & 18.3 & 18.3 & 18.3 \\
\hline Norway & Very high & 16.1 & 16.1 & 16.1 & 16.1 & 16.1 & 16.1 & 16.1 & 16.0 & 16.0 \\
\hline Portugal & Very high & 15.9 & 15.8 & 15.8 & 15.8 & 15.8 & 15.8 & 15.8 & 15.8 & 15.8 \\
\hline Sweden & Very high & 15.3 & 15.3 & 15.3 & 15.3 & 15.3 & 15.3 & 15.3 & 15.2 & 15.2 \\
\hline Turkey & Very high & 23.1 & 23.1 & 23.1 & 23.1 & 23.1 & 23.1 & 23.1 & 23.1 & 23.1 \\
\hline UK & Very high & 16.4 & 16.4 & 16.4 & 16.3 & 16.3 & 16.3 & 16.3 & 16.3 & 16.3 \\
\hline
\end{tabular}

Table 3 presents the welfare results from an analysis of the direct rebound where congestion and accident external costs are set to zero. This leaves behind only the air pollution and GHG emissions costs in the analysis. Of course, the external costs associated with air pollution and GHG emissions from burning a liter of gasoline in a car differ from the external costs associated with burning natural gas or coal to produce electricity. Nevertheless, we maintain the same fuel-related external costs just to show rough, indicative results of what the welfare outcomes might be for other energy services.

Table 3 reveals welfare enhancing direct rebound effects in most cases, given that the costs associated with direct rebound are considerably lower than before. This suggests that there may be a need to review the conventional wisdom that rebound is a negative phenomenon that requires mitigation. In fact, such welfare enhancing rebound effects may help improve the welfare outcomes of energy efficiency when accounted for, thus making energy efficiency more attractive to policymakers.

On a final note, we must emphasize that these results are suggestive. To accurately quantify the welfare implications of the direct rebound effect in energy services such as cooling and lighting, a different empirical framework would be needed. First, a demand curve for each energy service would need to be estimated and calibrated. Second, the external costs associated with the energy service would need to be estimated for each country. Nevertheless, the results in Table 3 suggest a pathway for future empirical research in this area.

Open Access This article is distributed under the terms of the Creative Commons Attribution 4.0 International License (http:// creativecommons.org/licenses/by/4.0/), which permits unrestricted use, distribution, and reproduction in any medium, provided you give appropriate credit to the original author(s) and the source, provide a link to the Creative Commons license, and indicate if changes were made.

\section{References}

Allan, G., Gilmartin, M., McGregor, P. G., Swales, K. J., \& Turner, K. (2009). Modelling the economy-wide rebound effect (book section), energy efficiency and sustainable consumption: the rebound effect. Macmillan: Palgrave. 
Azevedo, I. M. L. (2014). Consumer end-use energy efficiency and rebound effects. The Annual Review of Environment and Resources, 39(1), 393-418.

Barker T., Ekins, P., \& Foxon, T. (2007). The macro-economic rebound effect and the UK economy. Energy Policy, 35(10), 4935-4946.

Barker, T., Dagoumas, A., \& Rubin, J. (2009). The macroeconomic rebound effect and the world economy. Energy Efficiency, $2,411-427$.

Berkhout, P. H. G., Muskens, J. C., \& Velthuijsen, J. W. (2000). Defining the rebound effect. Energy Policy, 28(6-7), 425432.

Borenstein, S. (2015). A microeconomic framework for evaluating energy efficiency rebound and some implications. The Energy Journal, 36(1), 1-21.

Brookes, L. G. (1990). The greenhouse effect: the fallacies in the energy efficiency solution. Energy Policy, 18(2), 199-201.

Brookes, L. G. (1992). Energy efficiency and economic fallacies: a reply. Energy Policy, 20(5), 390-392.

Brookes, L. G. (1993). Energy efficiency fallacies: the debate concluded. Energy Policy, 21(4), 346-347.

Brown, M. A., \& Wang, Y. (2017). Energy-efficiency skeptics and advocates: the debate heats up as the stakes rise. Energy Efficiency, 10(5), 1155-1173.

Chan, N. W., \& Gillingham, K. (2015). The microeconomic theory of the rebound effect and its welfare implications. Journal of the Association of Environmental and Resource Economists, 2(1), 133-159.

Clinch, P. J., \& Healy, J. D. (2001). Cost-benefit analysis of domestic energy efficiency. Energy Policy, 29(2), 113-124.

Dahl, C. A. (2012). Measuring global gasoline and diesel price and income elasticities. Energy Policy, 41, 2-13.

Davis, L. W. (2017). The environmental cost of global fuel subsidies. The Energy Journal, 38. https://doi.org/10.3386 /w22105.

Dublin, J. A., Miedema, A. K., \& Chandran, R. V. (1986). The RAND Journal of Economics, 17(3), 310-325.

Dufournaud, C. M., Quinn, J. T., \& Harrington J. J. (1994). An applied general equilibrium (AGE) analysis of a policy designed to reduce the household consumption of wood in The Sudan. Resource and Energy Economics, 16(1), 67-90.

ExxonMobil. (2016). The outlook for energy: a view to 2040. Irving: ExxonMobil.

Frey, C. J., \& Labay, D. (1988). Examination of energy take-back. Energy Systems and Policy, 12, 205.

Gloger, S. (2011). Policies to overcome the rebound effect - a new challenge for environmental policy. Technical Report, Ministry of the Environment.

Greene, D. L. (1992). Vehicle use and fuel economy: how big is the "rebound" effect? The Energy Journal, 13(1), 117-143.

Greening, L. A., Greene, D. L., \& Difiglio, C. (2000). Energy efficiency and consumption - the rebound effect - a survey. Energy Policy, 28(6-7), 389-401.

Grepperud S., \& Rasmussen, I. (2004). A general equilibrium assessment of rebound effects. Energy Economics, 26(2), 261-282.

Henly, J., Ruderman, H., \& Levine, M. D. (1988). Energy savings resulting from the adoption of more efficient appliances: a follow-up. The Energy Journal, 9(2), 163-170.
Herring, H., \& Roy, R. (2007). Technological innovation, energy efficient design and the rebound effect. Technovation, 27(4), 194-203.

Hobbs, B. (1991). The "most value" test: economic evaluation of electricity demand-side management considering customer value. The Energy Journal, 12(2), 67-92.

Hunt, L. C., \& David, L. R. (2014). Catching on the rebound: Economic modelling of energy services and determining rebound effects resulting from energy efficiency improvements. Surrey Energy Economics Discussion Paper Series, Surrey Energy Economics Center.

IEA. (2016a). World energy statistics. Paris: International Energy Agency.

IEA. (2016b). Energy efficiency market report. Paris: International Energy Agency.

IMF. (2016). Getting energy prices right: from principles to practice. International Monetary Fund. http://www.imf. org/external/np/fad/environ/data/data.xlsx. Accessed on Feb 6, 2018.

Jevons, W. S. (1865). The coal question. London: Macmillan and Co..

Khazzoom, J. D. (1980). Economic implications of mandated efficiency in standards for household appliances. The Energy Journal, 1(4), 21-40.

Liang, Q. M., Fan, Y., \& Wei, Y. M. (2009). The effect of energy end-use efficiency improvement on China's energy use and CO2 emissions: A CGE model-based analysis. Energy Efficiency, 2(3), 243-262.

Maxwell, D., Owen, P., McAndrew, L., Muehmel, K., \& Neubauer, A. (2011). Addressing the rebound effect. A report for the European Commission DG Environment.

Menon, B. G. (2017). Empirical evidence of direct rebound effect in Indian two-wheeler sector. Energy Efficiency, 10(5), 12011213.

Otto, S., Kaiser, F. G., \& Arnold, O. (2014). The critical challenge of climate change for psychology: preventing rebound and promoting more individual irrationality. European Psychologist, 19(2), 96-106.

Ouyang, J., Long, E., \& Hokao, K. (2010). Rebound effect in Chinese household energy efficiency and solution for mitigating it. Energy, 35(12), 5269-5276.

Parry, I. W. H., Heine, D., Lis, E., \& Li, S. (2014). Getting energy prices right: from principle to practice. Washington, DC: International Monetary Fund.

Platts. (2016). Platts market data direct. London: Platts.

Reuters. (2016). Global market data. London: Reuters.

Roy, J. (2000). The rebound effect: some empirical evidence from India. Energy Policy, 28(6-7), 433-438.

Schwartz, J. (2005). The social benefits and costs of the automobile. In W. Cox, A. Pisarski, \& R. D. Utt (Eds.), 21st century highways: innovative solutions to America's transportation needs. Washington, DC: Heritage Foundation.

Small, K. A., \& Van Dender, K. (2007). Fuel efficiency and motor vehicle travel: the declining rebound effect. The Energy Journal, 28(1), 25-52.

Sorrell, S. (2009). "The rebound effect: definition and estimation", chapter 9 in the international handbook on the economics of energy. Cheltenham: Edward Elgar. 
Sorrell, S., \& Dimitropoulos, J. (2008). The rebound effect: microeconomic definitions, limitations and extensions. Ecological Economics, 65(3), 636-649.

Tang, C. (2017). Do speed cameras save lives? SERC Discussion Paper, 221.

van den Bergh, J. (2011). Energy conservation more effective with rebound policy. Environmental and Resource Economics, 48(1), 43-58.
Wei, T. (2010). A general equilibrium view of global rebound effects. Energy Economics, 32, 661-672.

World Bank. (2016). https://data.worldbank.org/indicator. Accessed on Feb 6, 2018.

Publisher's note Springer Nature remains neutral with regard to jurisdictional claims in published maps and institutional affiliations. 